\title{
Mediterranean sea water budget long-term trend inferred from salinity observations
}

\author{
N. Skliris ${ }^{1}$ (I) J. D. Zika ${ }^{2} \cdot$ L. Herold ${ }^{3} \cdot$ S. A. Josey ${ }^{4} \cdot$ R. Marsh $^{1}$
}

Received: 22 February 2017 / Accepted: 14 December 2017 / Published online: 10 January 2018

(c) The Author(s) 2018. This article is an open access publication

\begin{abstract}
Changes in the Mediterranean water cycle since 1950 are investigated using salinity and reanalysis based air-sea freshwater flux datasets. Salinity observations indicate a strong basin-scale multi-decadal salinification, particularly in the intermediate and deep layers. Evaporation, precipitation and river runoff variations are all shown to contribute to a very strong increase in net evaporation of order 20-30\%. While large temporal uncertainties and discrepancies are found between $E-P$ multidecadal trend patterns in the reanalysis datasets, a more robust and spatially coherent structure of multi-decadal change is obtained for the salinity field. Salinity change implies an increase in net evaporation of $\sim 8$ to $12 \%$ over 1950-2010, which is considerably lower than that suggested by air-sea freshwater flux products, but still largely exceeding estimates of global water cycle amplification. A new method based on water mass transformation theory is used to link changes in net evaporation over the Mediterranean Sea with changes in the volumetric distribution of salinity. The water mass transformation distribution in salinity coordinates suggests that the Mediterranean basin salinification is driven by changes in the regional water cycle rather than changes in salt transports at the straits.
\end{abstract}

Keywords Water cycle $\cdot$ Evaporation $\cdot$ Precipitation $\cdot$ Salinity $\cdot$ Water mass transformation $\cdot$ Mediterranean Sea

\section{Introduction}

The global water cycle, a key component of Earth's climate system, is expected to amplify with global warming, with wet regions becoming wetter and dry regions becoming drier (Held and Soden 2006; Hegerl et al. 2015). However, changes in the water cycle are hard to measure, mainly because of the lack of robust estimates of precipitation $(P)$ and evaporation $(E)$ over the ocean (e.g. Trenberth et al. 2007; Schanze et al. 2010; Hegerl et al. 2015). However, with the ocean receiving $80 \%$ of the total rainfall (Schanze et al. 2010), the salinity field is considered to be a "rain

N. Skliris

n.skliris@noc.soton.ac.uk

1 Ocean and Earth Science, University of Southampton, Southampton, UK

2 School of Mathematics and Statistics, University of New South Wales, Sydney, Australia

3 Ocean Physics and Modelling, University of Athens, Athens, Greece

4 National Oceanography Centre, Southampton, UK gauge", an integrator for changes in the water cycle (Terray et al. 2012). Salinity observations show much higher spatiotemporal coverage as compared to sparse direct observations of $E$ and $P$, substantially improving analyses of long-term variability at global scale. Recent studies demonstrated that the global spatial pattern of the mean near-surface salinity field has been significantly amplified since the 1950s with salinity increases (decreases) in evaporation (precipitation) dominated regions of the global ocean, suggesting a strong intensification of the water cycle (Boyer et al. 2005; Hosoda et al. 2009; Helm et al. 2010; Durack et al. 2012; Skliris et al. 2014b, 2016).

The Mediterranean is a semi-enclosed strongly evaporative basin (i.e. evaporation greatly exceeds precipitation and river runoff). As a consequence inflowing low salinity Atlantic surface waters (i.e. about 36.2 pss at the Strait of Gibraltar) are transformed into very saline Mediterranean intermediate and deep waters (with a deep water salinity of about 38.4 and 38.7 pss in western and eastern sub-basins, respectively). The density contrast between the highly saline Mediterranean Water and the relatively fresh Atlantic Water (AW) drives an inverse estuarine circulation in the Mediterranean. Mediterranean water of high salinity exits into 
the Atlantic, below the AW layer, and the net freshwater transport at the Gibraltar strait balances the freshwater loss through the surface.

The Mediterranean region is considered to be a 'hot-spot' for future climate changes (Giorgi 2006). It is a transitional region with a temperate climate under the influence of both the cooler/wetter European climate and the warmer/drier North African climate. Due to its size and limited exchange at the Gibraltar Strait changes in the air-sea fluxes cannot be compensated for by the Atlantic inflow but mainly by changes in its hydrological properties (Bethoux and Gentili 1999). In addition the Mediterranean has a very active thermohaline (overturning) circulation with various sites of deep water formation i.e. the South Adriatic [where the Adriatic Deep Water (ADW) is formed] and the South Aegean [where the Cretan Deep Water (CDW) is formed] in the Eastern Mediterranean (EMED), and the Gulf of Lions [where the Western Mediterranean Deep Water (WMDW) is formed] in the Western Mediterranean (WMED), inducing a rapid propagation of hydrological changes from the surface to the deepest parts of the basin (Fig. 1). The intensity of overturning circulation is controlled by the Levantine Intermediate Water (LIW), a very saline water mass formed through excessive heat loss and evaporation in the northeastern Levantine basin which then spreads westward at intermediate depths throughout the whole basin.

Uncertainty in quantifying the Mediterranean water and salt budgets is quite large due to the large temporal uncertainties associated to both the surface water fluxes and the fluxes through the Gibraltar Strait (Schroeder et al. 2012; Jordà et al. 2017). Numerical experiments show that even small changes in surface freshwater flux of the order of $10 \%$ of the mean freshwater budget can have large and long-term impacts on the thermohaline circulation and salt content of the Mediterranean Sea (Myers and Haines 2002; Skliris et al. 2007). Climate model projections indicate an accelerating warming and drying of the Mediterranean region during the twenty-first century (Somot et al. 2008; Mariotti et al. 2008, 2015; Giorgi and Lionello 2008). Mediterranean droughts over the last decades have been already associated with anthropogenically forced drying trends (Kelley et al. 2012), with the last 15 year (1998-2012) drought in the Levant (easternmost part of the Mediterranean region) being the driest in the last 500year record (Cook et al. 2016).

Consistent with the amplification of the global ocean water cycle and salinity mean patterns, the Mediterranean Sea underwent a strong salinification since the 1950s (Rohling and Bryden 1992; Bethoux and Gentili 1999; Rixen et al. 2005; Vargas-Yanez et al. 2010; Skliris et al. 2014b; Borghini et al. 2014; Schroeder et al. 2016). In particular, below $1000 \mathrm{~m}$ depth the Mediterranean basin exhibited the strongest salinity gain in the World Ocean since 1950 (Skliris et al. 2014b), whereas the increased salinity signal of the Mediterranean Overflow Water (MOW) is also clearly depicted at intermediate depths (1000-1500 m) in
Fig. 1 Geography and bathymetry map of the Mediterranean Sea. Main areas of dense water formation (black boxes) and dense water masses discussed in the text are also depicted. The Sicily Strait separates EMED and WMED sub-basins as defined in this study. Modified from Skliris (2014a)

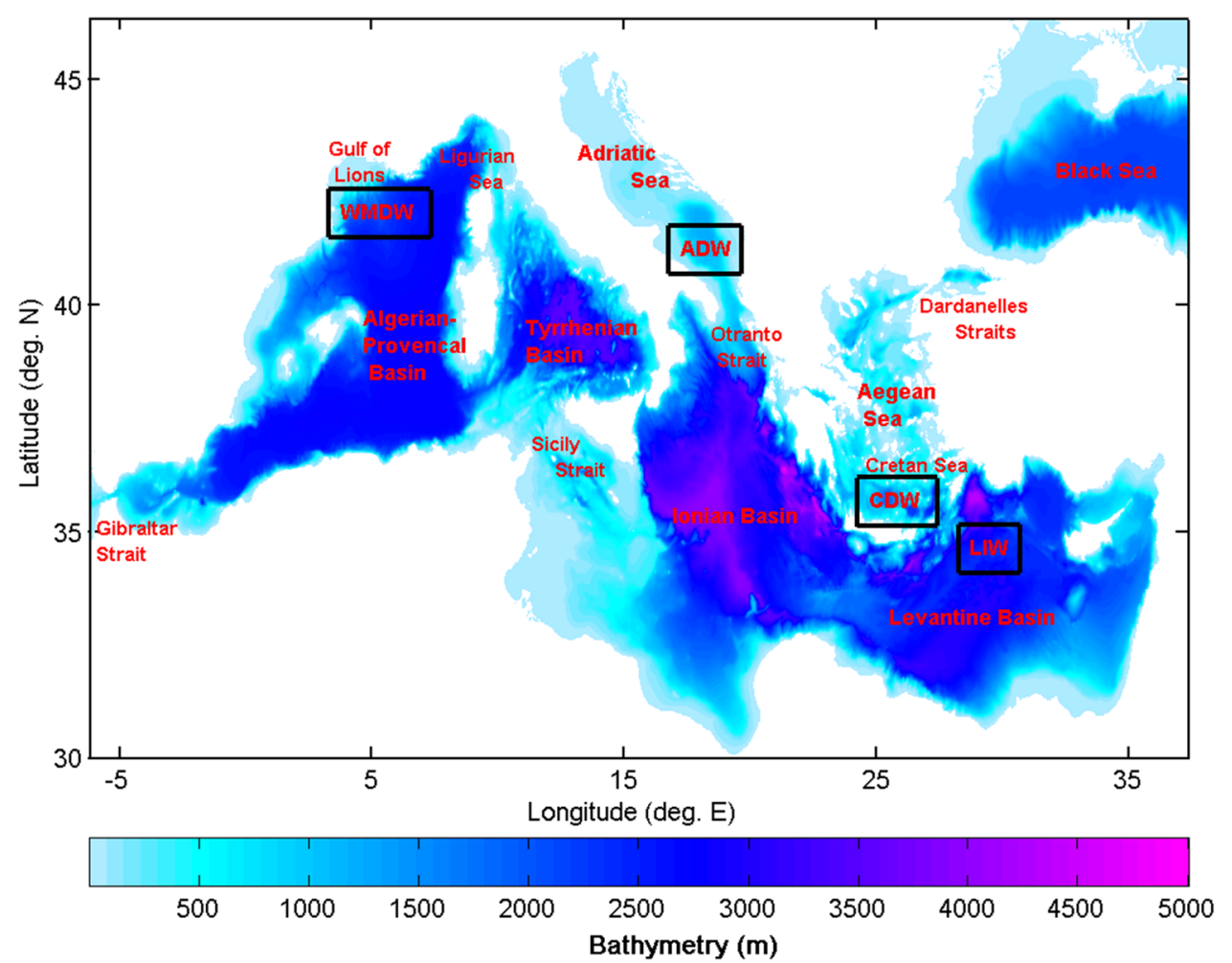


the subtropical North Atlantic (Curry et al. 2003; Potter and Lozier 2004; Skliris et al. 2014b).

Long-term salinity increasing trends in the Mediterranean are consistent with observed long-term changes in the various components of the water cycle, namely a long-term increase in $E$ driven by surface warming over the last few decades (e.g. Mariotti et al. 2002; Romanou et al. 2010; Skliris et al. 2012) combined with a decrease in $P$ from late 1960s to mid-1990s mainly associated with the North Atlantic Oscillation (NAO) multi-decadal variability (Krahmann and Schott 1998; Tsimplis and Josey 2001; Mariotti et al. 2002; Mariotti 2010) and a drastic reduction of river runoff $(R)$ attributed both to climate change and damming of major Mediterranean rivers since the 1960s (Rohling and Bryden 1992; Skliris and Lascaratos 2004; Skliris et al. 2007; Ludwig et al. 2009). There are no sufficient current velocity and salinity profile observations to estimate long-term water/salt transport variations at the Gibraltar and Dardanelles straits in order to assess their contribution in the salt and freshwater budgets of the basin. Observations at the Gibraltar Strait show a salinification of the Mediterranean outflow over the last few decades (Millot et al. 2006). On the other hand, AW can also be an important source of the Mediterranean salinity trend (Somot et al. 2016). Recent observational studies showed a large salinity increase in the Atlantic surface waters adjacent to the Gibraltar Strait over the 2000s, suggesting a significant contribution to the salinification of the Mediterranean Sea at shorter timescales (Millot 2007; SotoNavaro et al. 2012).

The overall objective of this paper is to provide new insights into the link between salinity changes and the changing water cycle of the Mediterranean Sea at multi-decadal scales using available observational salinity and reanalysis-based air-sea freshwater flux datasets. In particular, we use a new thermodynamic method (Zika et al. 2015; Skliris et al. 2016) based on the water mass transformation theory (Walin 1977, 1982) to explain changes in the Mediterranean water cycle from the observed three-dimensional pattern of salinity change. The water mass transformation distribution in salinity coordinates allows to assess the relative contribution of changes in salt transports through the straits and in surface freshwater fluxes in producing the strong broad-scale salinification of the Mediterranean basin.

\section{Methods and data}

\subsection{Datasets}

In general it is difficult to distinguish between long-term water cycle changes induced by regional patterns of global climate change and multi-decadal anomalies induced by natural large scale modes of atmospheric variability such as NAO affecting the Mediterranean climate with periods of the order of 2-3 decades. Hence, in order to detect robust multi-decadal climatic trends in salinity and the water cycle, time-series should span significantly longer than a few decades to filter out most of natural climate multi-decadal oscillations.

Multi-decadal salinity changes in the Mediterranean Sea are investigated here using two datasets: (a) the MEDATLAS database (MEDAR Group 2002) consisting of temperature and salinity profiles in the Mediterranean from 1945 to 2002 interpolated onto a $0.2^{\circ} \times 0.2^{\circ}$ horizontal grid and a vertical grid of 25 levels by a variational inverse model (Rixen et al. 2005) and (b) the UK Met Office Hadley Centre Enhanced Ocean Data Assimilation and Climate prediction (ENACT) archive version4 (EN4, subversion En4.1.1, http://www. metoffice.gov.uk/hadobs/en4) objectively-analysed monthly dataset covering the $1950-2015$ period, at $1^{\circ} \times 1^{\circ}$ horizontal grid and a vertical grid of 42 levels (Good et al. 2013).

Both datasets are using high-level quality checked salinity data. Although there is a well-known problem with XBT failing rate issue in the older MEDATLAS dataset (which is corrected in the more recent En4 database used here) VargasYanez et al. (2010) showed that the omission of XBT data from the time series resulted in no significant change in the long-term temperature trends throughout the Mediterranean basin while salinity trends remained unchanged.

Both gridded datasets have been previously routinely employed in studies of the Mediterranean long-term variability (e.g. Rixen et al. 2005; Vargas-Yanez et al. 2010; Adani et al. 2011; Sevault et al. 2014; Hamon et al. 2016). However there are limitations in their use especially in the representation of trends. The quality of objective analysis and variational inverse methods used to fill the data gaps in order to obtain gridded 3-D continuous timeseries clearly varies spatially depending on the availability of input data to which they are constrained. Hence observational coverage strongly limits the representation of long-term variability and trends in the deep layers of the Mediterranean and over earlier decades of the record, in particular. There are consequences for trend analysis with a general tendency for underestimation of trend magnitude as climatology is used to fill spatio-temporal gaps in the observational record (Llasses et al. 2014). In order to evaluate the representation of long-term salinity trends from the two gridded databases we compared these trends with estimates from previous observational studies (Table 1) for specific regions/layers and time periods based on various observational networks where sufficiently long time-series exist (i.e. at least 10 years). Results show indeed an underestimation of trends for both gridded datasets in the majority of cases, typically of order $10-30 \%$, but reaching $\sim 50 \%$ in a couple of cases. There are no significant differences between EN4 and MEDATLAS-derived salinity trends. 
Table 1 Salinity trends (pss/ decade) in various areas of the Mediterranean Sea (at specific depths or depth-averaged) from individual in-situ observations and from the inter-annual objectively-analysed gridded En4 and MEDATLAS datasets used in this study

\begin{tabular}{|c|c|c|c|}
\hline & & En4 & MEDATLAS \\
\hline \multicolumn{4}{|l|}{ West Med., $0^{\circ}-10^{\circ} \mathrm{E},<42^{\circ} \mathrm{N}$} \\
\hline 2000 m depth, 1955-1989 & 0.009 & $0.008 \pm 0.005$ & $0.007 \pm 0.005$ \\
\hline \multicolumn{4}{|l|}{ Rohling and Bryden (1992) } \\
\hline \multicolumn{4}{|l|}{ Ligurian Sea } \\
\hline 200-600 m, 1950-1999 & $0.014 \pm 0.0010$ & $0.007 \pm 0.0004$ & $0.012 \pm 0.006$ \\
\hline 600-2500 m, 1950-1996 & $0.015 \pm 0.0010$ & $0.008 \pm 0.002$ & $0.009 \pm 0.002$ \\
\hline \multicolumn{4}{|l|}{ Vargas-Yanez et al. (2010) } \\
\hline \multicolumn{4}{|l|}{ Ligurian Sea (DYFAMED) } \\
\hline 1800-2000 m, 1995-2005 & $0.027 \pm 0.013$ & $0.033 \pm 0.012$ & \\
\hline \multicolumn{4}{|l|}{ Borghini et al. (2014) } \\
\hline \multicolumn{4}{|l|}{$\mathrm{NW}$ Med, $0^{\circ}-10^{\circ} \mathrm{E},>39^{\circ} \mathrm{N}$} \\
\hline 0-70 m, 1960-1990 & $0.043 \pm 0.0010$ & $0.061 \pm 0.037$ & $0.054 \pm 0.044$ \\
\hline \multicolumn{4}{|l|}{ Krahmann and Scott (1998) } \\
\hline \multicolumn{4}{|l|}{ Algerian-Provencal Basin } \\
\hline 2000-2700 m, 1959-1997 & 0.011 & $0.007 \pm 0.004$ & $0.009 \pm 0.002$ \\
\hline \multicolumn{4}{|l|}{ Béthoux et al. (1998) } \\
\hline \multicolumn{4}{|l|}{ Gulf of Lions } \\
\hline 1675-2450 m, 1955-1994 & $0.008 \pm 0.001$ & $0.006 \pm 0.004$ & $0.008 \pm 0.004$ \\
\hline \multicolumn{4}{|l|}{ Krahmann and Scott (1998) } \\
\hline \multicolumn{4}{|l|}{ Gulf of Lions } \\
\hline 600-2500 m, 1952-1995 & $0.012 \pm 0.010$ & $0.007 \pm 0.002$ & $0.009 \pm 0.002$ \\
\hline \multicolumn{4}{|l|}{ Vargas-Yanez et al. (2010) } \\
\hline \multicolumn{4}{|l|}{ Tyrrhenian Sea } \\
\hline 600-2500 m, 1951-1992 & $0.009 \pm 0.005$ & $0.008 \pm 0.004$ & $0.007 \pm 0.006$ \\
\hline \multicolumn{4}{|l|}{ Vargas-Yanez et al. (2010) } \\
\hline \multicolumn{4}{|l|}{ Eastern Alboran Sea } \\
\hline 200 m-bottom, 1961-2008 & $0.015 \pm 0.003$ & $0.010 \pm 0.004$ & \\
\hline \multicolumn{4}{|l|}{ Borghini et al. (2014) } \\
\hline \multicolumn{4}{|l|}{ Sicily Strait } \\
\hline 400 m depth, 1993-2016 & $0.060 \pm 0.020$ & $0.035 \pm 0.018$ & \\
\hline \multicolumn{4}{|l|}{ Schroeder et al. (2017) } \\
\hline \multicolumn{4}{|l|}{ Ionian Basin } \\
\hline 1200 m-bottom, 1955-1999 & 0.011 & $0.010 \pm 0.007$ & $0.008 \pm 0.007$ \\
\hline \multicolumn{4}{|l|}{ Manca et al. (2004) } \\
\hline \multicolumn{4}{|l|}{ East Levantine } \\
\hline 135-350 m, 1979-2014 & $0.050 \pm 0.030$ & $0.034 \pm 0.021$ & \\
\hline Ozer et al. (2016) & & & \\
\hline
\end{tabular}

The Mediterranean Sea Physics Re-analysis 1955-2015 (https://doi.org/10.25423/MEDSEA_REANALYSIS_ PHY_006_009, Fratianni et al. 2015) is used here to construct long-term annual timeseries of salt fluxes at the Gibraltar strait (upper layer salt influx, lower layer salt outflux, and net salt flux). This is a monthly product based on a high-resolution (at $1 \% 116 \times 1 \% / 16$ horizontal grid with 72 depth levels) Nucleus for European Modelling of the Ocean (NEMO) general circulation model used in Mediterranean Sea operational forecasting (Oddo et al. 2009). The model is extended into the Atlantic Ocean where it is one-way nested with a low-resolution $\left(1 / 4^{\circ} \times 1 / 4^{\circ}\right)$ global ocean climatological model. It is combined with a 3-D variational assimilation scheme using all historical in-situ 3-D temperature and salinity and satellite observations (Dobricic and Pinardi 2008; Adani et al. 2011). Surface momentum, heat, and water fluxes are computed by bulk formulae adapted to the Mediterranean case using Atmospheric Model Intercomparison Project (AMIP) data (Cherchi and Navarra 2007). Heat and $E$ fluxes are constrained by SST observations (HadSST1 dataset, Rayner et al. 2003), $P$ is taken from the Climate Prediction Centre Merged Analysis of Precipitation (CMAP) Data (Xie and 
Arkin 1997) and river runoff is taken from the Global Runoff Data Centre dataset (Fekete et al. 1999).

Two atmospheric reanalysis-based $E-P$ datasets are used covering the 1950-2010 period: the NCEP/NCAR Reanalysis 1 spanning 1948-present (Kistler et al. 2001) and the twentieth century reanalysis (20CRv2), spanning 1871-present (Compo et al. 2011). We should note that NCEP/NCAR and 20CRv2 re-analyses used here are not independent as they both use an NCEP Numerical Weather Prediction (NWP) model. The primary difference between the two is that 20CRv2 assimilates a restricted range of data types (just sea level pressure with SST as a boundary condition) whereas input data to NCEP/NCAR covers a wide range of variables (Compo et al. 2011; Kistler et al. 2001). Taking this issue into account, we examine E-P trends in the two datasets, expecting a reasonable level of agreement due to the lack of independence. Moreover a hybrid $E-P$ product, partially based on observational/satellite-derived data, is also used here to compare with the two re-analysis products over a shorter common period (1979-2010). $E$ is provided by the Objectively Analyzed air-sea Fluxes (OAFlux) dataset (http://rda.ucar.edu/datasets/ds260.1/), that blends NCEP and ERA-40 reanalysis products with satellite surface meteorology through an objective synthesis (monthly mean data on a $1^{\circ} \times 1^{\circ}$ grid, available from 1958 ), while $P$ is obtained from the Global Precipitation Climatology Project (GPCP v2.2, http://rda.ucar.edu/datasets/ds728.2/) (monthly mean data on a $2.5^{\circ} \times 2.5^{\circ}$ grid, available from 1979 ).

Global reanalysis and GPCP products have been routinely used in various studies of the Mediterrranean water cycle/salt budget (Krahmann and Schott 1998; Tsimplis and Josey 2001; Mariotti et al. 2002, 2008; Romanou et al. 2010). Previous studies show a relatively good agreement between reanalyses and coastal station/satellite-derived precipitation in the Mediterranean Sea. NCEP re-analysis precipitation is consistent with CMAP observational data (Xie and Arkin 1997) based on rain gauge data and satellite retrievals (Mariotti et al. 2002). NCEP also show consistent $\mathrm{E}$ and $\mathrm{P}$ trends over the Mediterranean with satellite retrievals from the Hamburg Ocean Atmosphere Parameters and Fluxes from Satellite Data (HOAPS-3) dataset (Romanou et al. 2010). In a recent study Hatzianastasiou et al. (2016) showed that the GPCPv2 satellite precipitation data over the Mediterranean were well correlated with rain gauge measurements from 433 stations while they were also compared well with the higher spatial and temporal resolution Tropical Rainfall Measuring Mission (TRMM) data. Nastos (2011) also showed that the trends of gridded GPCP data (1980-2009) were in a good agreement against those from coastal stations.

A common problem when estimating long-term trends in the E-P field using re-analyses or blended re-analysis/ satellite-derived products is the inhomogeneities arising in the time series due to the changing observing system and the inclusion of new (mainly satellite) data sources (e.g. Schanze et al. 2010). Major transition events in data composition include the beginning of the Outgoing Longwave Radiation (OLR) Precipitation Index (OPI) mission (1979), and, in particular, the inclusion of SSM/I data (1987), which greatly increased spatial and temporal resolution in these datasets (Schanze et al. 2010). As a consequence, analysis for both 1950-2010 and 1979-2010 periods considered here is affected by these discontinuities in data composition, compromising trend estimates. As for salinity data, E-P data are also considerably more uncertain during earlier decades in the record, due to poor spatiotemporal coverage of the observational data assimilated in the NWP simulations. Another source of uncertainty in atmospheric re-analyses is that they do not explicitly take into account changes in the Green House Gas (GHG) or aerosol forcing, although the associated variability is, at least partially, implicitly taken into account through assimilation of various observed surface meteorological parameters (such as SST, sea level pressure, air temperature over land, etc.).

The total river runoff trend in the Mediterranean is based on the estimate of Ludwig et al. (2009) covering the 1960-2000 period ( $-0.0057 \mathrm{~m} /$ year/decade). Significant river runoff changes in the Mediterranean started in the early-mid 1960s due to damming of major rivers (e.g. damming resulted in dramatic river runoff reductions of Nile and Ebro river runoff). The longer-term Dai et al. (2009) dataset for the whole Mediterranean and Black sea region shows no significant changes before the 1960s. Also in a recent study Sevault et al. (2014) estimating total Mediterranean river runoff inter-annual changes over 1980-2012 showed no statistically significant change after 2000 while annual timeseries closely following that of Ludwig et al. (2009) resulting in an identical (negative) trend value over 1980-2000. Therefore we assumed no change in river runoff over periods before 1960 or after 2000 so that the total river runoff mean $(0.14 \mathrm{~m} /$ year $)$ and trend $(-0.0057 \mathrm{~m} /$ year $/ \mathrm{dec}$ ade) over 1950-2010 is considered to be the same as over 1960-2000.

\subsection{Salt approximate conservation equation}

Salinity observations at individual locations are not appropriate to infer water cycle changes since surface signals are rapidly advected by ocean surface currents. However by integrating 3-D salinity changes over the ocean one may filter out the rearrangement of saline and fresh waters from ocean currents. By quantifying the increase of anomalously salty and fresh waters i.e. the amplification of the mean 3-D salinity pattern, one may infer changes in the water cycle.

Here we assess water cycle change in the Mediterranean Sea through observed 3-D salinity changes using two different 
methods. In the first method the net evaporation change is inferred from the Mediterranean volume-averaged salinity change and net salt flux changes at the straits connecting the Mediterranean basin with the adjacent basins, using an approximate salt conservation equation:

$$
\begin{aligned}
\rho_{M}(t) S_{M}(t) V_{M}(t)= & \rho_{M}(t) S_{M}(t+\Delta t)\left(V_{M}(t)+\Delta h_{F W} A_{M}\right) \\
& +\rho_{G} \Delta V S_{G}(t+\Delta t)+\rho_{D} \Delta V S_{D}(t+\Delta t),
\end{aligned}
$$

where $\rho$ is in situ volume-averaged density $\left(\mathrm{kg} / \mathrm{m}^{3}\right), S_{M}$ is the Mediterranean volume-averaged salinity, $V_{M}$ is the Mediterranean total volume, $t$ is time, $\Delta t$ is an integration time step, $A_{M}$ is the total Mediterranean sea surface area, $\Delta h_{F W}$ is the additional height (m) per unit area of freshwater accumulated or lost over the entire Mediterranean surface due to change in net evaporation, $\Delta V S$ is the change in net salt transport at the straits connecting the Mediterranean basin with the adjacent basins [i.e. Gibraltar Strait (G) - exchange with the Atlantic Ocean, and Dardanelles Strait (D) - exchange with the Black Sea]. The net salt flux at the Gibraltar Strait is calculated by the monthly ocean reanalysis described before. The Dardanelles Strait net salt flux could not be determined here due to the lack of observations or ocean re-analysis outputs (the ocean reanalysis used here applies climatological flux at the Dardanelles Strait). Stanev and Peneva (2002) investigating the evolution of the Bosphorus volume transport (estimated as a residual from $E-P-R$ and sea volume change calculated by the time rate of observed sea level change) showed an increasing trend over the second half of the twentieth century suggesting increasing BSW inflow in the Aegean Sea. However the authors speculated that such conditions would have contributed to dilution of the Aegean Sea, but more plausible would be to assume that the exchange at the open boundaries and at air-sea interface tended to compensate for this slow trend. Taking into account that volume fluxes at the Dardanelles Strait are an order of magnitude lower than those of the Gibraltar Strait, the Dardanelles net salt flux is neglected in this study. Moreover, salt flux exchange at the Suez Canal is also neglected here.

\subsection{Water mass transformation framework}

In the second approach water cycle changes are linked to changes in the volumetric distribution in salinity coordinates using a new thermodynamic method developed by Zika et al. (2015), based on the water mass transformation theory (Walin 1977, 1982), as explained below.

The movement of an individual water parcel in salinity coordinates is given by:

$\frac{d S}{d t}=S_{o}(E-P-R)+\nabla \cdot K \nabla S$, where $S_{0}$ is the volume-averaged mean salinity and $K$ is a positive definite diffusion tensor. A water parcel changes its salinity, $S$, through surface freshwater flux $(E-P-R)$ and salt mixing. Considering the volume of seawater bound by the isohaline $\mathrm{S}=\mathrm{S} *$ given by:

$V\left(S^{*}\right)=\iiint_{S<S *} d x d y d z$,

The total movement of freshwater across the isohaline surface $\mathrm{S}=\mathrm{S} *$ is given by integrating both RHS terms of Eq. (2):

$$
\begin{aligned}
M T R= & \frac{d V\left(S^{*}\right)}{d t}=\iiint_{S<S *} \delta\left(S-S^{*}\right)\left(S_{o}(P+R-E)\right. \\
& -\nabla \cdot K \nabla S) d x d y d z,
\end{aligned}
$$

where $\delta$ is a dirac delta function.

Equation (4) states that the rate of change in the volume of water in salinity coordinates $\mathrm{d} V(S) / d t$, i.e. the Mass Transformation $(M T R)$ rate, is set by the water cycle (i.e. $P+R$ $-E$ ) and salt mixing. A positive $M T R$ rate denotes a transformation from saline to fresh water and a negative $M T R$ rate denotes a transformation from fresh to saline water. As the water cycle amplifies over the global ocean, positive water mass transformation occurs over the fresh regions (with respect to global mean salinity) and negative transformation occurs over the salty regions, i.e. fresh regions become fresher and salty regions become saltier. On the other hand, in an amplifying water cycle salt mixing acts in the opposite direction, i.e. as the salinity contrast between water masses increases salt mixing also increases, thus partially counterbalancing the water cycle effect.

If we integrate (4) in salinity coordinates (i.e. from low salinity to high salinity) we get:

$$
\begin{aligned}
F W T\left(S^{*}\right)= & \frac{1}{S_{o}} \int_{0}^{S^{*}} \frac{d V\left(S^{*}\right)}{d t} d S=\frac{1}{S_{o}} \int_{0}^{S^{*}} \operatorname{MTR}\left(S^{*}\right) d S \\
= & W C\left(S^{*}\right)+\operatorname{MIX}\left(S^{*}\right) \\
= & \iiint_{S<S *} \Pi\left(S-S^{*}\right)(P+R-E) d x d y d z, \\
& -\frac{1}{S_{o}} \iiint_{S<S *} \Pi\left(S-S^{*}\right) \nabla \cdot K \nabla S d x d y d z,
\end{aligned}
$$

where $\Pi\left(S-S^{*}\right)$ is a step function $\left(\Pi=0\right.$ for $S<S^{*}$ and $\Pi=1$ for $S>S^{*}$ ).

The LHS term of Eq. (5) is the accumulated Fresh Water Transport in salinity space FWT, where the first and second RHS terms of Eq. (5) are the accumulated isohaline freshwater transport by the water cycle $(W C)$ and salt mixing (MIX), respectively. At steady state $F W T$ equals to zero, so that $W C=M I X$, i.e. the volumetric distribution in salinity coordinates is maintained by the opposing effects of the 
water cycle (which broadens the volumetric distribution as salinity contrast increases) and salt mixing (which tends to collapse the volumetric distribution as it always takes salt from the saltiest water and mix it with the fresh water). In a changing climate due to global warming the water cycle amplifies ( $W C$ term increases) leading to an increase in the $F W T$ term while at the same time $M I X$ term also increases partially counteracting the water cycle amplification.

If we ignore the salt mixing term $(M I X)$ the peak value in $F W T$ distribution in $S$ space provides an estimate of the change of the water cycle amplitude. In regions of net evaporation such as the Mediterranean Sea a negative peak denotes the total increase of net evaporation (i.e. total accumulated freshwater volume removed from the basin) and a positive peak denotes the total decrease of net evaporation (total accumulated freshwater volume added in the basin). Equation (5) generally stands for an enclosed system i.e. the global ocean or an enclosed oceanic basin. In the case of a semi-enclosed basin such as the Mediterranean Sea, the $F W T$ term also includes the freshwater displacement due to changes in the transports at the straits.

Here we use the observed change in the volumetric distribution in salinity coordinates $(\Delta V(S))$ over a considered period (based on the calculation of the 3-D salinity trends) in the two datasets (En4 over 1950-2015; MEDATLAS over 1950-2002) to calculate the $M T R$ rate $(d V(S) / d t)$ and $F W T$ term. Following Eq. (5) we may then link $F W T$ to changes in Mediterranean net evaporation, and salt mixing over the considered period. We should stress that Eq. (5) is not used here to infer the water cycle change [this is performed by using the salt approximate conservation Eq. (1) as described above] as it is very difficult to estimate the salt mixing term only from salinity observations. Here we calculate $F W T$ and MTR rate (at basin-scale and at the various straits of the basin) and combined with Eq. (1) we assess the relative importance of the various processes contributing to the salt content change. En4 3-D salinity field is interpolated onto the higher resolution MEDATLAS 3D grid before calculating salt content changes and performing the water mass transformation analysis in salinity space.

\subsection{Timeseries, linear trends and uncertainty estimates}

For the GPCP product where there is no defined sea-land mask available, a fractional approach was applied to take into account the actual sea coverage of GPCP grid cells i.e. we weight the grid-cell values by their actual sea coverage percentage before averaging in space. First we construct monthly anomaly time series for all monthly datasets by subtracting the mean seasonal cycle from the monthly data at each grid point. Annual anomalies are then constructed from the monthly anomalies, allowing us to compute linear trends in the three-dimensional salinity and $E-P$ fields. All linear trends have been computed by least square fitting, and trend errors are defined at the $95 \%$ confidence interval. We modify the confidence intervals around the regression coefficients to account for the violation of the model assumption of non-autocorrelated errors, using heteroscedasticity and autocorrelation (HAC) robust standard errors calculated by MATLAB (R2016a). The p-value for statistical significance of a correlation coefficient between two timeseries is computed by transforming the correlation to create a t-statistic having $\mathrm{N}-2$ degrees of freedom, where $\mathrm{N}$ is the number of data in the timeseries.

\section{Results}

\subsection{Surface freshwater flux changes}

Figure 2 shows spatial patterns of trends in $E, P$, and $E-P$ from the two reanalyses over 1950-2010. Although there is a strong multi-decadal variability both re-analyses show a long-term net evaporation increase over most of the Mediterranean surface, driven by combined evaporation increases and precipitation decreases. Precipitation trend shows a broad-scale pattern of decreasing values almost throughout the basin, whilst evaporation trend shows much larger spatial variability with both increasing and decreasing values. The $E-P$ trend averaged over the whole Mediterranean surface over 1950-2010 (20CRv2: 0.023 $\pm 0.008 \mathrm{~m} /$ year/ decade; NCEP: $\sim 0.015 \pm 0.010 \mathrm{~m} /$ year/decade) accounts for $\sim 20$ and $\sim 12 \%$ of the mean for 20CRv2 and NCEP, respectively. The long-term basin-average E-P trend seems to be mainly driven by a decrease in $P$ roughly over mid-1960's to mid-1990 s and a strong increase in $E$ after the mid-1970 s (Fig. 3).

Both reanalyses show higher area-averaged net evaporation increase (with respect to sub-basin mean net evaporation) in WMED (NCEP/NCAR: 32\%, 20CRv2: 35\%) than in EMED (NCEP/NCAR: 8\%, 20CRv2: 18\%) (see Fig. 3). All three products used here (NCEP, 20CRv2, and OAFlux) show quasi-steady increases in $E$ after the mid-1970's. This is also consistent with ship air-sea flux measurements showing strongly increasing latent heat loss over the Eastern Mediterranean mainly attributed to the rapid surface warming over this period (Skliris and Lascaratos 2004; Skliris et al. 2012). Also both re-analyses show a large reduction in $P$ roughly occurring from the mid-1960s to mid-1990s, largely driving the net evaporation long-term increase in WMED, which is mainly attributed to an increasingly positive phase of NAO over this period (e.g. Tsimplis and Josey 2001; Mariotti et al. 2002; Romanou et al. 2010). Strong statistically significant correlations were found between NCEP/ NCAR as well as 20Rv2 precipitation and GPCP detrended 

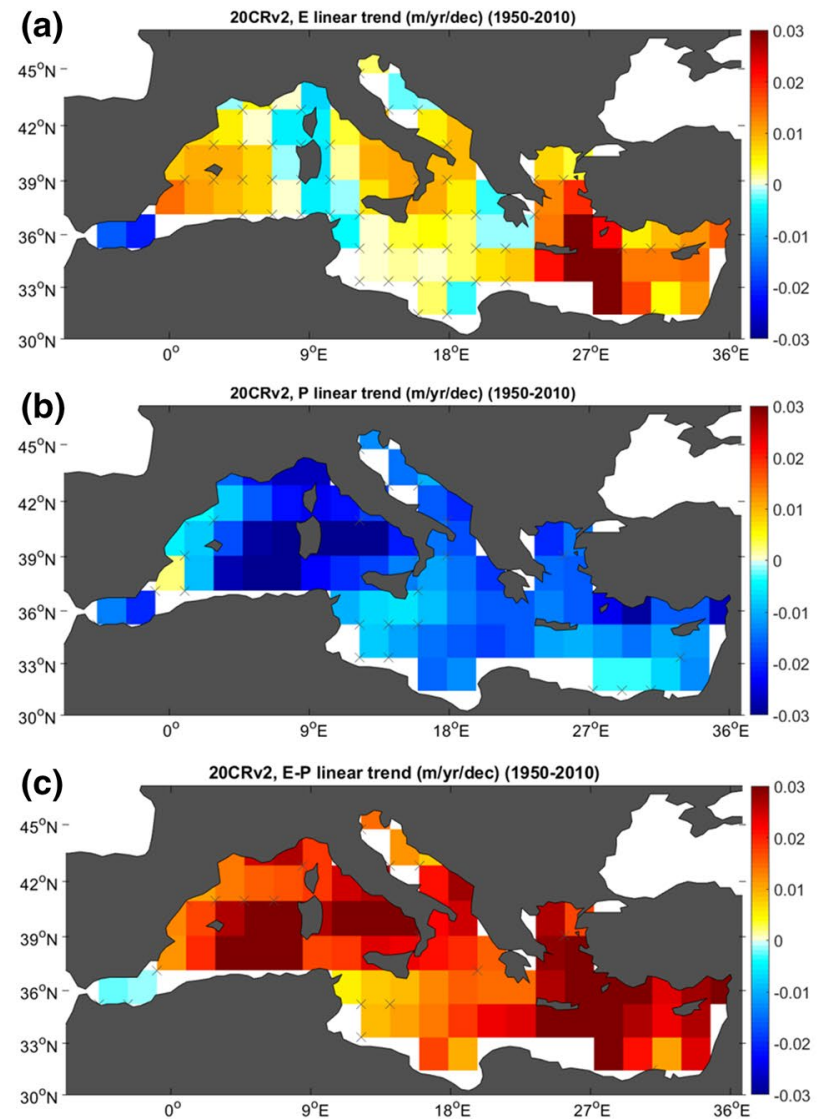
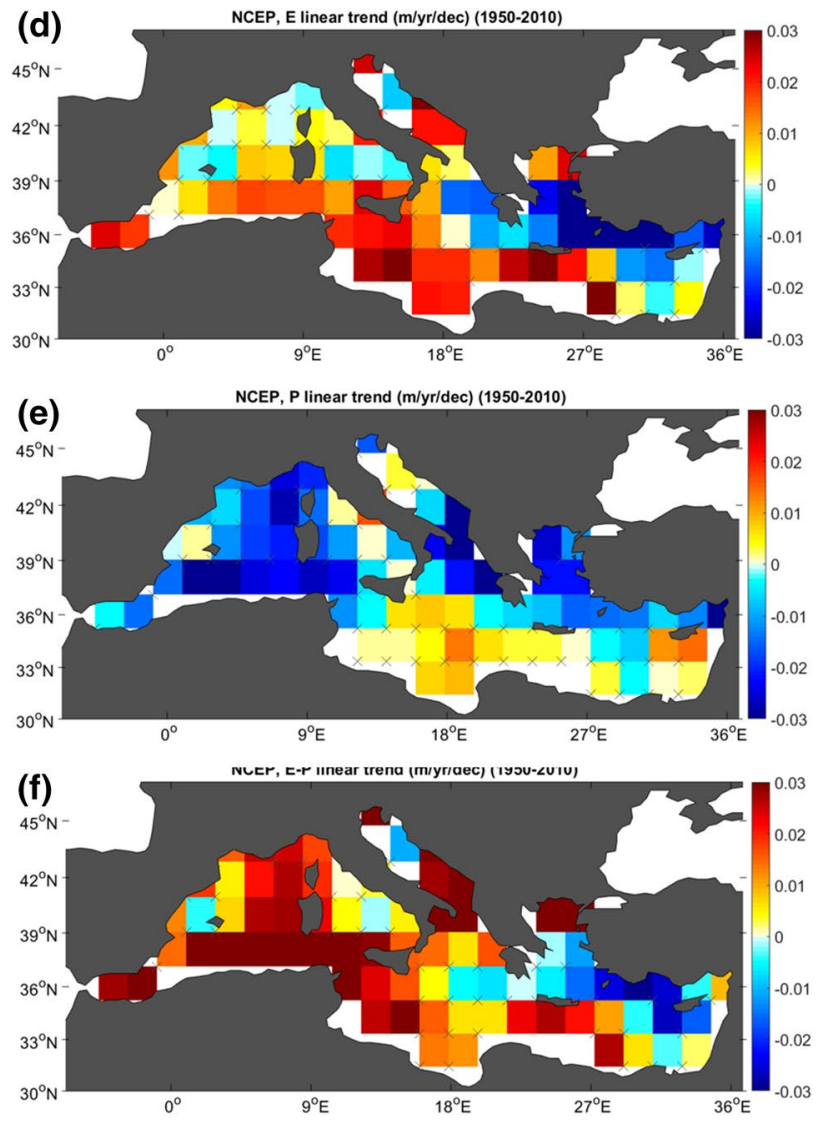

Fig. $2 E(\mathbf{a}, \mathbf{d}), P(\mathbf{b}, \mathbf{e})$, and $E-P(\mathbf{c}, \mathbf{f})$ linear trends over 1950-2010 (m/year/decade) from 20CRv2 (left panels) and NCEP/NCAR (right panels). Regions where the linear trend is not significant at the $95 \%$ confidence level are stippled in gray

timeseries over 1979-2010 (i.e. $r=0.79$ for NCEP/NCAR and $r=0.80$ for 20CRv2, respectively). However, uncertainty estimates of long-term trends are very large $(>50 \%$ of the mean), whilst there is evidence of large differences in the long-term trend magnitude in some locations and even opposite sign between the two reanalyses in EMED. In particular, in the Levantine basin, NCEP/NCAR, in contrast with 20CRv2, exhibits a long-term decreasing $E-P$ trend. In general NCEP shows much larger multi-decadal variability in EMED with decreasing (increasing) $E$ over roughly the first (last) half part of the record resulting in much less pronounced and not statistically significant area-averaged long-term trends in $E$ and $E-P$ (see Table 2).

Figure 4 shows annual timeseries of $E, P$, and $E-P$ averaged over the whole Mediterranean surface from the two re-analyses and the OAFlux-GPCP dataset. It is interesting to note that the hybrid OAFlux-GPCP dataset shows a much stronger net $E-P$ increase of $\sim 44 \%$ over the shorter 1979-2010 period, which is largely driven by increasing $E$. This feature is not reproduced in the two re-analyses which show considerably lower $E-P$ increases over the same period (20CRv2: 15\%; NCEP 10\%). This is chiefly due to much lower $E$ increase in $20 \mathrm{CRv} 2$ and to a strong
$P$ increase in NCEP/NCAR over the last two decades partially counterbalancing evaporation increases.

Climatological mean $E-P$ flux over the whole Mediterranean surface $\left(\sim 2.510^{12} \mathrm{~m}^{2}\right)$ amounts to $0.057 \mathrm{~Sv}$ (Sverdrup, $1 \mathrm{~Sv}=10^{6} \mathrm{~m}^{3} / \mathrm{s}$ ) for NCEP/NCAR and $0.056 \mathrm{~Sv}$ for 20CRv2, with these values being within previous re-analysis or hybrid re-analysis/satellite-derived estimates ranging from 0.039 to $0.070 \mathrm{~Sv}$ (Mariotti et al. 2002; Sanchez-Gomez et al. 2011) and close to the $E-P$ mean value derived by the hybrid OAFlux-GPCP dataset used here over 1979-2010 ( 0.050 Sv). Adding the total climatological mean river discharge from Ludwig et al. (2009) of $\sim 0.011 \mathrm{~Sv}$ we get a mean net $E-P-R$ flux of $0.045-0.046 \mathrm{~Sv}$ for the two re-analyses. Based on the linear trends, net $E-P$ change over 1950-2010 amounts to $0.0070 \pm 0.0047 \mathrm{~Sv}$ for NCEP/NCAR and $0.0111 \pm 0.0046 \mathrm{~Sv}$ for $20 \mathrm{CR} v 2$, respectively. Adding a decrease in total river discharge of $\sim 0.0027 \mathrm{~Sv}$ over this period (Ludwig et al. 2009) we get a net $E-P-R$ change ranging $0.0097-0.0138 \mathrm{~Sv}$. This indicates a quite large increase in net evaporation of the whole basin ranging 20-30\% over 1950-2010. 

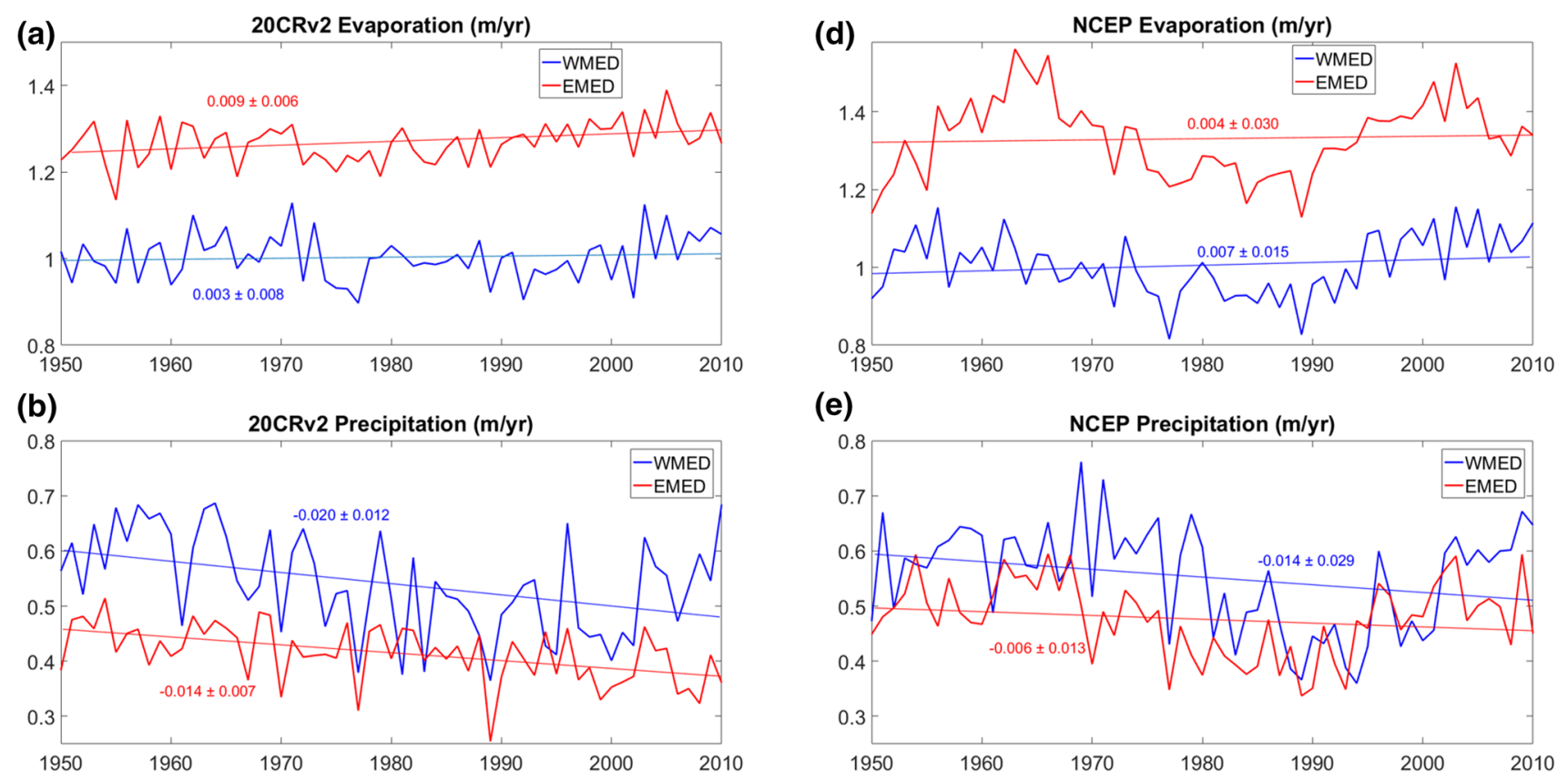

(c)
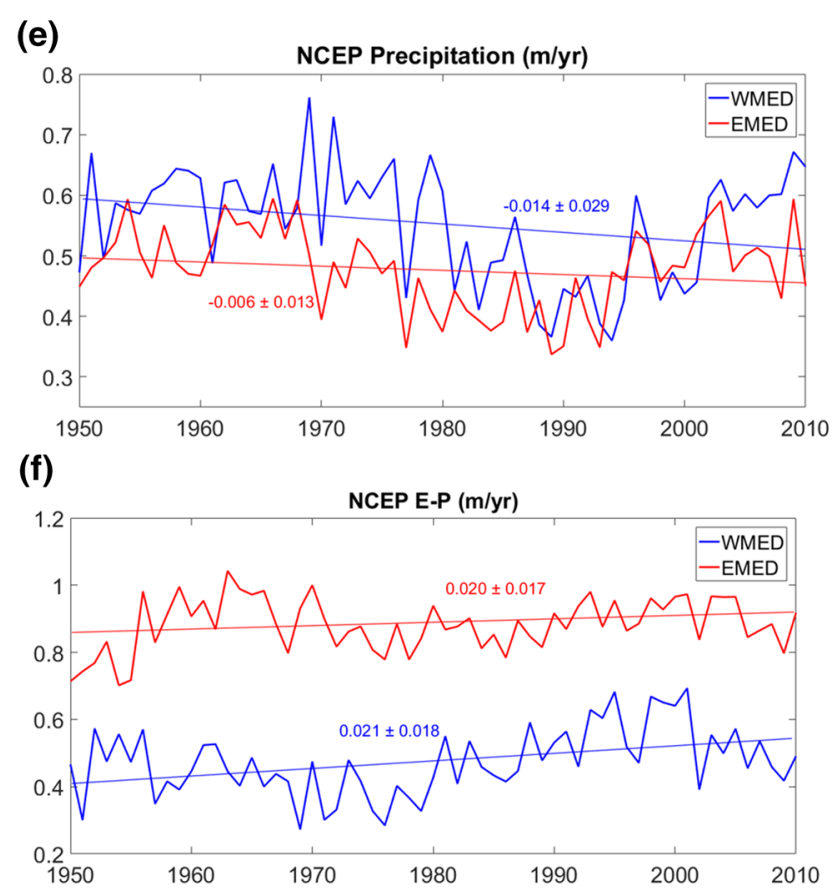

Fig. 3 Mediterranean area-averaged annual timeseries of $E$ (a), $P$ (b), and $E-P$ (c) in m/year over 1950-2010 from 20CRv2 (red) and NCEP/NCAR (blue). Annual timeseries of Evaporation from OAF-

\subsection{Salinity changes}

Figure 5 shows the spatial pattern of salinity trend in the upper $150 \mathrm{~m}$ layer, the 150-600 $\mathrm{m}$ layer (typical of LIW presence), and the bottom layer (>600 $\mathrm{m}$ depth) of the Mediterranean basin. There is more spatial variability in the salinity trend over 1950-2002 (common period of the two datasets) when a few freshening pools are still observed, especially in the upper $150 \mathrm{~m}$ layer, whereas much stronger positive salinity trends are observed throughout the whole basin over 1950-2015, except from the upper layer of the North Aegean Sea. Volume averaged salinity increase exceeds $0.015 \mathrm{pss} / \mathrm{dec}$ de in the upper $150 \mathrm{~m}$ layer in both west (WMED) and east (EMED) Mediterranean sub-basins (Fig. 6). Largest upper layer salinity increases exceeding $0.04 \mathrm{pss} / \mathrm{decade}$ are obtained in the easternmost part of the Mediterranean, consistent with the observed strong increase in latent heat loss there since the early 1970s (Mariotti 2010;

lux (1958-2010) (black) and Precipitation from GPCP (1979-2010) (black) are also depicted. Trend values (m/year/decade) are also depicted

Skliris et al. 2012) and the large reduction in Nile river runoff since the early 1960s (Skliris and Lascaratos 2004).

Annual timeseries of total volume-averaged salinity show important decadal variability, especially in the upper layer, characterised by roughly three distinct periods: (a) 1950 s to late 1960s with no significant trend, (b) early 1970s to mid$1990 \mathrm{~s}$ with a moderate increasing salinity trend, and (c) from mid-1990 s onwards with a much stronger increasing salinity trend (Fig. 6d).

The strong deep water formation in both EMED and WMED and the very active Mediterranean thermohaline overturning circulation seem to induce a rapid propagation of upper layer increasing salinity signals into the deeper layers. In addition to deep water formation events, double-diffusive salt finger processes are also shown to transfer near surface salinity change signals into the WMDW (Bryden et al. 2014). Superimposed to the long-term trend, strong decadal signals associated with climate transient events drive larger 
Table $2 E$, $P$, and $E-P$ linear trends (m/year/decade) in MED, WMED, and EMED, from NCEP/NCAR and $20 \mathrm{CRv} 2$ over 1950-2010 and over 1979-2010

\begin{tabular}{|c|c|c|c|c|c|c|}
\hline & \multicolumn{6}{|l|}{ 20CRv2 } \\
\hline & \multicolumn{2}{|l|}{$\mathrm{E}$} & \multicolumn{2}{|l|}{$\mathrm{P}$} & \multicolumn{2}{|l|}{ E-P } \\
\hline & 1950-2010 & 1979-2010 & 1950-2010 & 1979-2010 & 1950-2010 & 1979-2010 \\
\hline MED & $0.0064 \pm 0.0062$ & $0.0231 \pm 0.0134$ & $-0.0161 \pm 0.0072$ & $-0.0047 \pm 0.0197$ & $0.0230 \pm 0.0077$ & $0.0269 \pm 0.0191$ \\
\hline WMED & $0.0025 \pm 0.0077$ & $0.0184 \pm 0.0181$ & $-0.0203 \pm 0.0124$ & $0.0200 \pm 0.0312$ & $0.0228 \pm 0.0115$ & $-0.0016 \pm 0.0294$ \\
\hline \multirow[t]{4}{*}{ EMED } & $0.0089 \pm 0.0064$ & $0.0250 \pm 0.0200$ & $-0.0141 \pm 0.0066$ & $-0.0197 \pm 0.0175$ & $0.0230 \pm 0.0092$ & $0.0450 \pm 0.0162$ \\
\hline & \multicolumn{6}{|l|}{ NCEP/NCAR } \\
\hline & \multicolumn{2}{|l|}{$\mathrm{E}$} & \multicolumn{2}{|l|}{$P$} & \multicolumn{2}{|l|}{$\mathrm{E}-\mathrm{P}$} \\
\hline & 1950-2010 & 1979-2010 & 1950-2010 & 1979-2010 & 1950-2010 & 1979-2010 \\
\hline MED & $0.0049 \pm 0.0214$ & $0.0625 \pm 0.0319$ & $-0.0095 \pm 0.0179$ & $0.0450 \pm 0.0241$ & $0.0144 \pm 0.0120$ & $0.0187 \pm 0.0278$ \\
\hline WMED & $0.0070 \pm 0.0154$ & $0.0622 \pm 0.0409$ & $-0.0141 \pm 0.0289$ & $0.0387 \pm 0.0578$ & $0.0213 \pm 0.0179$ & $0.0247 \pm 0.0419$ \\
\hline \multirow[t]{4}{*}{ EMED } & $0.0036 \pm 0.0300$ & $0.0625 \pm 0.0419$ & $-0.0066 \pm 0.0134$ & $0.0491 \pm 0.0200$ & $0.0204 \pm 0.0166$ & $0.0150 \pm 0.0219$ \\
\hline & \multicolumn{2}{|l|}{ OAFlux } & \multicolumn{2}{|l|}{ GPCP } & \multicolumn{2}{|l|}{ OAFlux-GPCP } \\
\hline & \multicolumn{2}{|l|}{$\mathrm{E}$} & \multicolumn{2}{|l|}{$\mathrm{P}$} & \multicolumn{2}{|l|}{$E-P$} \\
\hline & & 1979-2010 & & 1979-2010 & & 1979-2010 \\
\hline MED & & $0.0841 \pm 0.0281$ & & $-0.00146 \pm 0.0114$ & & $0.0856 \pm 0.0259$ \\
\hline WMED & & $0.0972 \pm 0.0359$ & & $0.0101 \pm 0.0306$ & & $0.0947 \pm 0.0381$ \\
\hline EMED & & $0.0753 \pm 0.0263$ & & $-0.0071 \pm 0.00259$ & & $0.0825 \pm 0.0241$ \\
\hline
\end{tabular}

Changes in evaporation from OAFlux and precipitation from GPCP over 1979-2010 are also depicted

salinity increases around the deep water formation sites (see Fig. 5b, c, e, f). In particular, we find largest salinity increases of order $0.015 \mathrm{pss} /$ decade at intermediate/deep layers of the South Aegean Sea linked with the Eastern Mediterranean Transient over the late 1980s/early 1990s (Klein et al. 1999; Theocharis et al. 1999), and at the bottom layer of the Ligurian-Provencal basin mainly associated with the Western Mediterranean Transient (WMT), a climatic shift started in mid-2000s with several strong deep water formation events abruptly increasing bottom layer salinity (e.g. Schroeder et al. 2016). Full-depth volume-averaged salinity change over 1950-2015 in En4 is stronger in WMED $(0.079 \pm 0.011)$ than in EMED $(0.059 \pm 0.013)$ (Fig. 6d; Table 3). Basin total salt content variations since 1950s seem to roughly follow $E-P$ variations (as derived from the two reanalyses), with the positive trend picking up in the early 1970s and accelerating after the early 1990s. However, correlations between basin total salt content and reanalysis E-P annual timeseries, although statistically significant, are relatively small over $1950-2010$ (20CRv2/En4: $\mathrm{R}=0.54$, $\mathrm{p}<0.05 ; \mathrm{NCEP} / \mathrm{En} 4: \mathrm{R}=0.33, \mathrm{p}<0.05$ ), while a larger correlation is found between salt content (En4) and E-P from OAFlux/GPCP over the 1979-2010 period $(\mathrm{R}=0.67$, $\mathrm{p}<0.05$ ). However there was no statistical significant correlation between detrended timeseries. Acceleration of salt content increase over the last few decades is coincident with the acceleration of surface warming and subsequent increase of latent heat loss over the Mediterranean surface (Skliris et al. 2012) (see Table 3).

\subsection{Salinity-inferred water cycle change}

We may now infer water cycle (net evaporation) change from Eq. (1) using the basin total volume salt content change and the change in net salt transports at the straits. Mediterranean Sea Physics Re-analysis shows increasing both salt influx and outflux at the Gibraltar Strait resulting in a small net salt outflux trend of $\sim 0.005 \times 10^{6} \mathrm{~kg} / \mathrm{s} /$ year over 1955-2015 (Fig. 7). The increase in the net salt outflux is a small fraction $(\sim 5 \%)$ of the actual total basin salt content increase derived from the En4 volume average salinity trend over the same period. The Mediterranean total volume salt content increase in En4 and the net salt outflux from the ocean re-analysis give a net evaporation increase of $\sim 0.00315 \pm 0.00104 \mathrm{~Sv}$ over 1950-2010. Considering a climatological mean net evaporation over the Mediterranean surface of $0.039 \mathrm{~Sv}$ (i.e. mean $E-P$ from OAFlux-GPCP minus climatological mean $R$ from Ludwig et al. 2009) this amounts to a net evaporation increase of $\sim 8.1 \pm 2.7 \%$ over 1950-2010. This estimate is about 3-4 times lower than the atmospheric reanalysis-based estimates over the same period (i.e. 20-30\%). En4 and MEDATLAS-derived net 


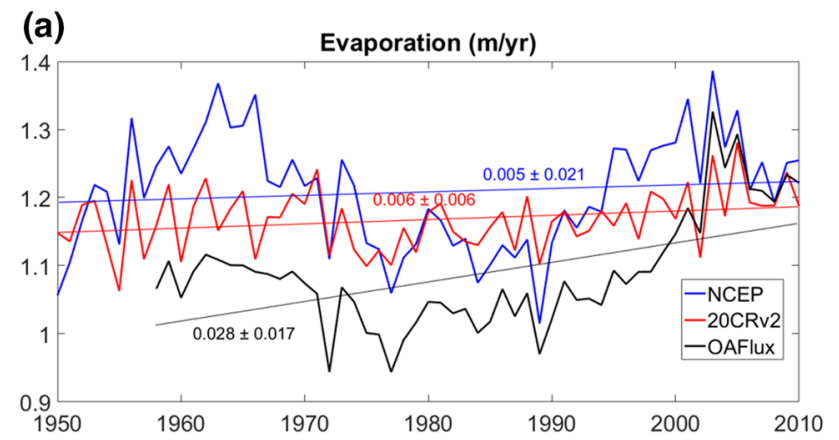

(b)

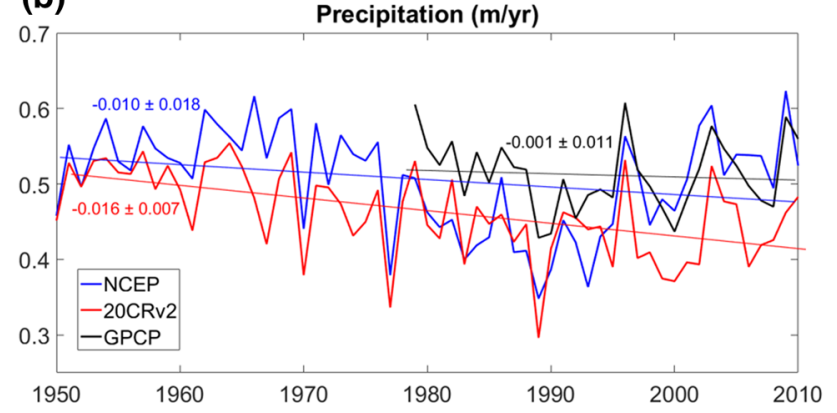

(c)

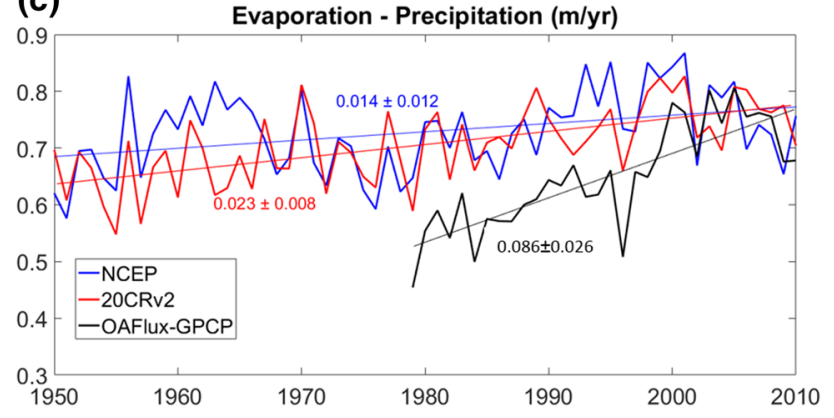

Fig. $4 E(\mathbf{a}, \mathbf{d}), P(\mathbf{b}, \mathbf{e})$, and $E-P(\mathbf{c}, \mathbf{f})$ annual timeseries over 1950 2010 (m/year) from 20CRv2 (left panels) and NCEP/NCAR (right panels) over WMED (blue lines) and EMED (red lines). Trend values $(\mathrm{m} /$ year/decade) are also depicted

evaporation increase over the common period 1950-2002 amounts to $6.1 \pm 2.5$ and $5.1 \pm 2.6 \%$ respectively (i.e. $~ 20 \%$ discrepancy).

\subsection{Water mass transformation and water cycle change in salinity space}

Water mass transformation in salinity space is subsequently inferred from the observed 3-D salinity change field in the two salinity datasets using the water mass transformation framework described above. Figure 8a, b shows the Mediterranean Sea volumetric distribution in salinity space $\mathrm{V}(\mathrm{S})$ discretised here by intervals of $\Delta S=0.05$ pss [i.e. volume of seawater $\left(\mathrm{m}^{3}\right)$ per 0.05 pss interval] in the two salinity datasets. The volumetric distribution has two distinct peaks around 38.4 and 38.7 pss, representative of the mean WMED and EMED deep water properties, respectively. Volumetric change $\Delta \mathrm{V}(\mathrm{S})$ since 1950 clearly shows a displacement of both volumetric peaks towards higher salinity in both datasets. Cumulative water mass transformation rate in salinity space $(d V(S) / d t)$ is almost everywhere negative indicating a freshwater transport from more saline to less saline waters throughout the basin (i.e. salty waters become saltier) peaking at the volumetric peaks of the two sub-basins (Fig. 8c). In En4 (1950-2015) maximum transformation rate is higher in WMED i.e. $0.4 \mathrm{~Sv}$ encountered at the salinity bin at $\sim 38.4$ pss than in EMED i.e. $\sim-0.3 \mathrm{~Sv}$ at the salinity bin at $\sim 38.7$ pss. This means that freshwater is transported at a rate of $\sim 0.4 \mathrm{~Sv}$ from the volume of seawater between salinities 38.4-38.45 pss towards lower salinities over the considered period. Both datasets indicate that the transformation rate is very small at low salinities representative of inflowing AW (from 36.5 pss in the Alboran Sea to $\sim 38.2$ pss in easternmost part of EMED) and Black Sea Water (BSW) $(<36.5$ pss in the northeast Aegean Sea). En4 dataset shows stronger water mass transformation rates at higher salinities (> $38.7 \mathrm{pss}$ ), typical of EMED, as compared to MEDATLAS over the common period 1950-2002. The total accumulated isohaline freshwater transport (Fig. 8d) over 1950-2002 (from Eq. 5) is about 20\% larger in En4 $(0.00234 \pm 0.00067 \mathrm{~Sv})$ as compared to MEDATLAS $(0.00192 \pm 0.00165 \mathrm{~Sv})$ although this difference is within uncertainty estimates for the two datasets. It is about $30 \%$ larger over 1950-2015 $(0.00308 \pm 0.00120 \mathrm{~Sv})$ and almost two times larger over $1979-2015(0.00430 \pm 0.00190 \mathrm{~Sv})$ as compared to 1950-2002 in the En4 dataset, consistent with an accelerated salinification over the last two decades (see Fig. 6).

When freshwater transformation analysis is made separately in the two sub-basins (not shown) the total volume of transformed (saltier) waters is comparable in EMED and WMED (i.e. it is only 20\% larger in EMED) although the total water volume of the latter is approximately two times larger, consistent with the much larger salinification rate of WMED.

Figure 9 shows local water mass transformation analysis in the main Mediterranean straits (Gibraltar, Sicily, and Dardanelles) using the higher resolution MEDATLAS dataset (1950-2002). At the Gibraltar Strait results show a very large negative freshwater transformation in the lower layer (salinities higher than $38 \mathrm{pss}$ ) suggesting a strong salinification of the Mediterranean outflow. Transformation is also negative within characteristic salinities of AW, suggesting an increased salt inflow in the upper layer, however transformation rates are much smaller as compared with waters of Mediterranean origin. In the case of the Dardanelles straits again much stronger (negative) transformation occurs in the deep layer filled with Mediterranean waters whereas very small positive transformation rates of freshwater (indicating net 

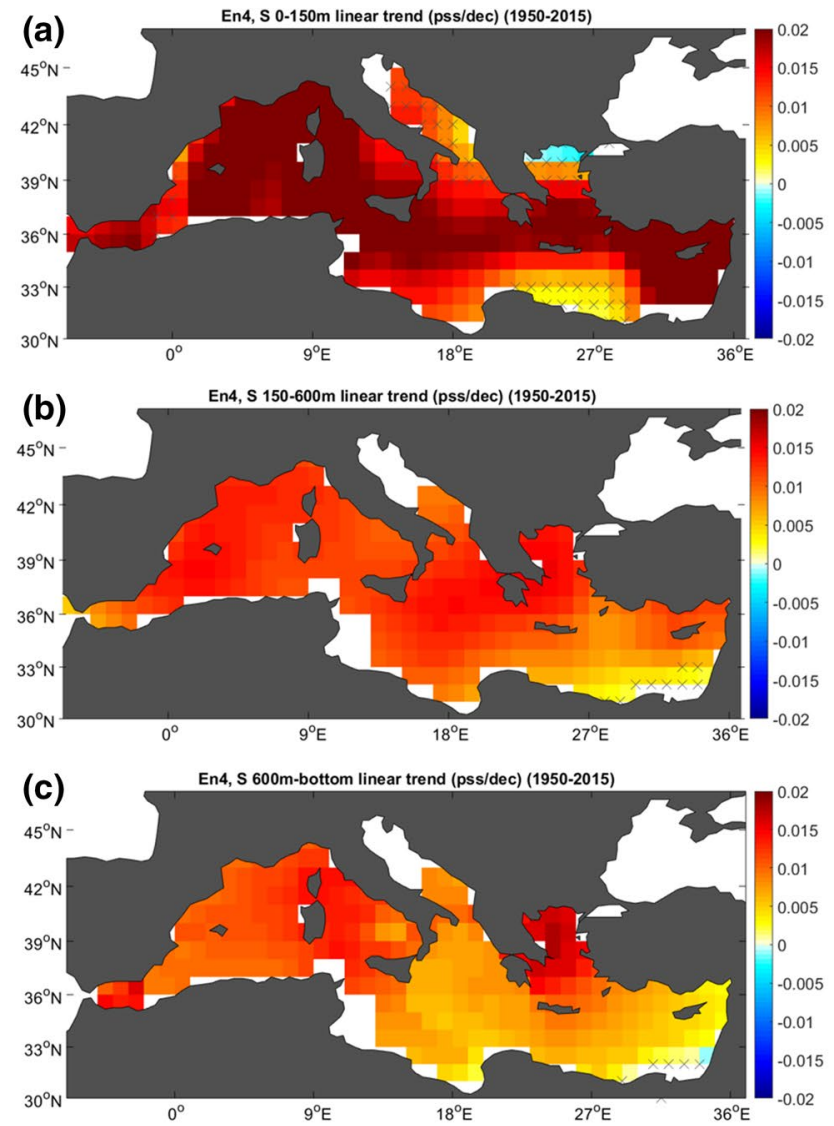

Fig. 5 Salinity linear trends (pss/decade) from MEDATLAS over 1950-2002 (left panels), and En4 over 1950-2015 (right panels), averaged over the 0-150 $\mathrm{m}$ layer $(\mathbf{a}, \mathbf{d})$, the $150-600 \mathrm{~m}$ layer $(\mathbf{b}, \mathbf{e})$,

freshening) in the upper layer inflowing waters. The freshwater transformation pattern at the Sicily Strait connecting the two sub-basins is comparable with that of Gibraltar/ Dardanelles straits, showing much larger water mass transformation rates in the bottom layer filled with saltier intermediate water produced in the eastern Mediterranean (i.e. mainly LIW) as compared to the upper layer of inflowing MAW. Therefore apart from larger net evaporation increase in WMED, as evidenced in the two atmospheric re-analyses, strong salinification of LIW over this period spreading from EMED through the bottom layer of the Sicily Strait into WMED seems to contribute to the larger salt content increase in WMED as compared to EMED.

\subsection{Salinity volumetric distribution and salt mixing}

Equation (5) links the accumulated freshwater transport (FWT) calculated by the change in the volumetric distribution in salinity space to changes in the water cycle and salt mixing. In the global ocean, the water cycle amplification results in increasing the salinity contrast between water masses and thus stretching the volumetric distribution in
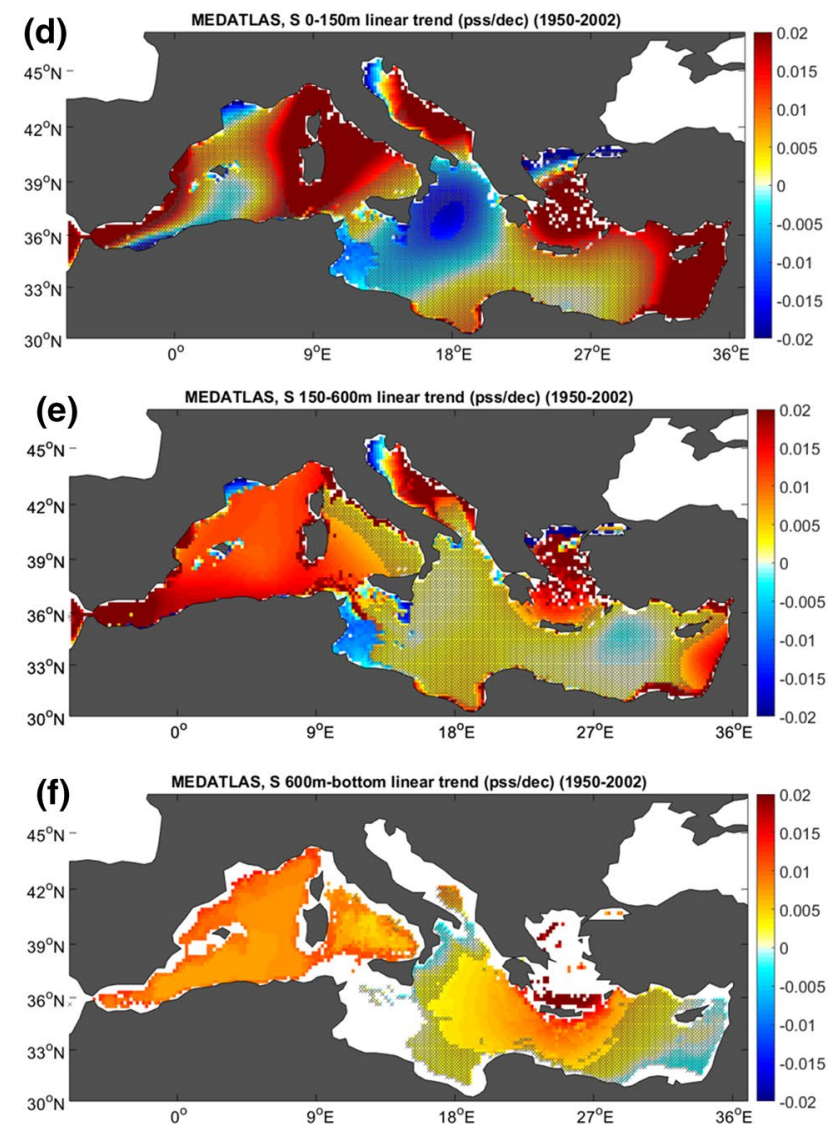

and the 600 m-bottom layer (c, f). Regions where the linear trend is not significant at the $95 \%$ confidence level are stippled in grey

salinity space (as salty waters getting saltier and fresh waters getting fresher) which in turn leads to enhanced salt diffusion fluxes between isohaline volumes (Zika et al. 2015; Skliris et al. 2016). Therefore the change in salt mixing is expected to act in the opposite direction, reducing the freshwater transport in salinity space (i.e. mixing will always take salt from the saltiest waters and mix it with the less saline waters), thus partially compensating for the stretching of the volumetric distribution by the water cycle increase. Skliris et al. (2016) based on the same thermodynamic method and using state-of-the-art coupled climate models to investigate global ocean water cycle changes showed that the exclusion of the mixing term in Eq. (4) underestimated the accumulated isohaline freshwater displacement by the water cycle by $\sim 20 \%$ over the historical period. However, in contrast with the global ocean, characterised by a freshwater budget close to balanced (accumulated $E-P-R \sim 0$ ), the Mediterranean is an evaporation basin (accumulated $E-P-R>0$ ), so that the net evaporation increase leads to salinity increases almost throughout the basin. In both datasets considered here the whole volumetric distribution is displaced towards higher salinities (see Fig. 8a, b). However, if saltier waters 
(a)

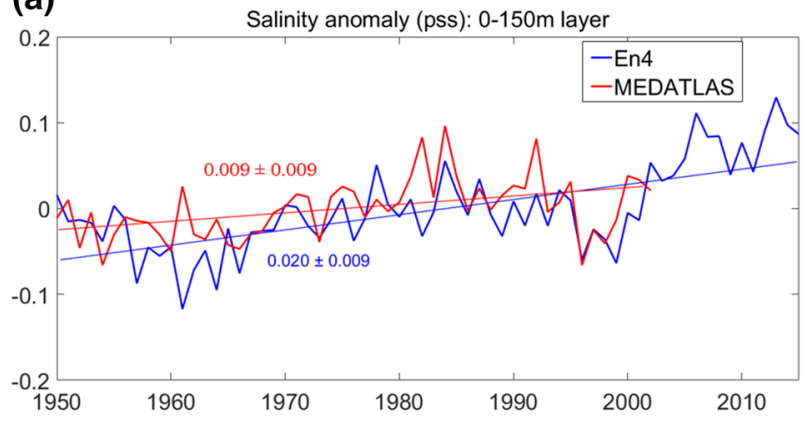

(b)

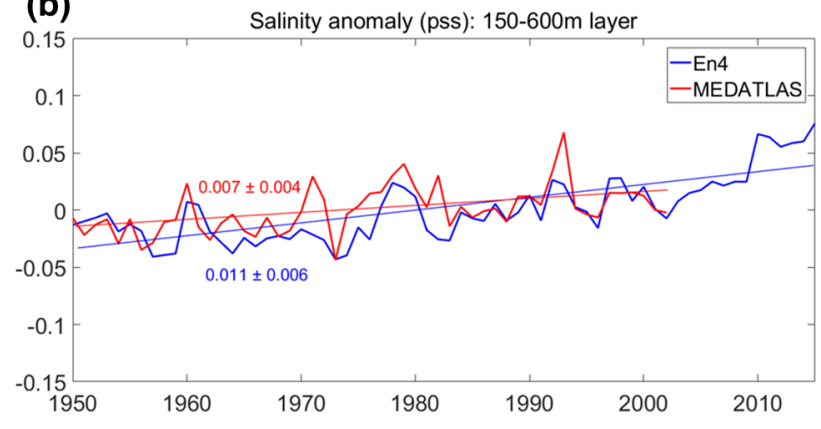

Fig. 6 Mediterranean volume-averaged salinity anomaly (pss) annual timeseries derived from En4 (1950-2015) and MEDATLAS (1950-2002) datasets in three layers: a 0-150 m, b 150-600 m, and c 600 m-bottom and $\mathbf{d}$ for full depth: for En4 (1950-2015, solid lines) (c)

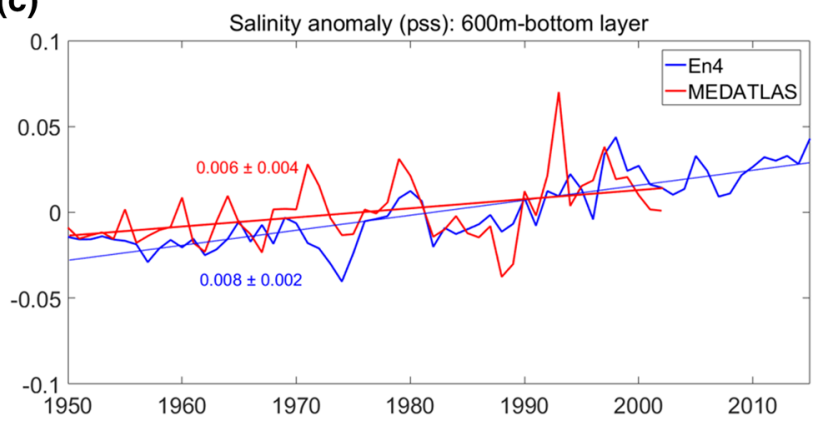

(d)

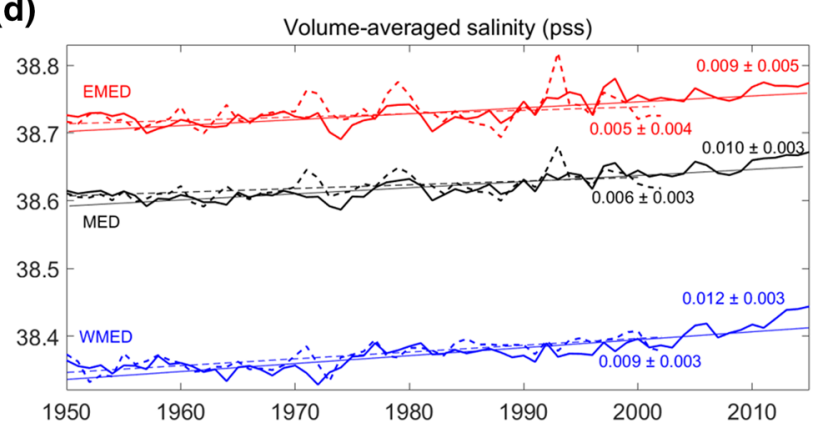

and MEDATLAS (1950-2002, dashed lines) for the whole basin (MED, black), eastern sub-basin (EMED, red) and western sub-basin (WMED, blue). Trend values (pss/decade) are also depicted
Table 3 Volume-averaged salinity linear trends (pss/ decade) in MED, WMED, and EMED, in MEDATLAS (1950-2002) and En4 (19502002 and 1950-2015) for full depth, and for the $0-150$, 150-600, and $600 \mathrm{~m}$-bottom layers, respectively

\begin{tabular}{llll}
\hline & MEDATLAS $(1950-2002)$ & En4 (1950-2002) & En4 (1950-2015) \\
\hline Full depth & & & \\
MED & $0.0063 \pm 0.0023$ & $0.0077 \pm 0.0037$ & $0.0100 \pm 0.0034$ \\
WMED & $0.0090 \pm 0.0026$ & $0.0090 \pm 0.0040$ & $0.0120 \pm 0.0035$ \\
EMED & $0.0046 \pm 0.0040$ & $0.0071 \pm 0.0038$ & $0.0089 \pm 0.0045$ \\
$0-150 \mathrm{~m}$ & & & \\
MED & $0.0088 \pm 0.0092$ & $0.0096 \pm 0.0077$ & $0.0196 \pm 0.0094$ \\
WMED & $0.0142 \pm 0.0148$ & $0.0058 \pm 0.0110$ & $0.0200 \pm 0.0139$ \\
EMED & $0.0060 \pm 0.0113$ & $0.0112 \pm 0.0073$ & $0.0180 \pm 0.0080$ \\
150-600 m & & & \\
MED & $0.0067 \pm 0.0036$ & $0.0067 \pm 0.0040$ & $0.0110 \pm 0.0060$ \\
WMED & $0.0123 \pm 0.0040$ & $0.0092 \pm 0.0038$ & $0.0120 \pm 0.0059$ \\
EMED & $0.0035 \pm 0.0048$ & $0.0050 \pm 0.0042$ & $0.0109 \pm 0.0060$ \\
600 m-bottom & & & \\
MED & $0.0058 \pm 0.0040$ & $0.0081 \pm 0.0042$ & $0.0083 \pm 0.0020$ \\
WMED & $0.0075 \pm 0.0021$ & $0.0092 \pm 0.0027$ & $0.0111 \pm 0.0021$ \\
EMED & $0.0048 \pm 0.0058$ & $0.0073 \pm 0.0054$ & $0.0071 \pm 0.0020$ \\
\hline
\end{tabular}

become saltier at a higher rate than the less salty waters then the width of volumetric distribution will again increase leading to increased salt mixing between isohaline volumes. Although this is clearly evidenced between the relatively fresh AW and the very salty upper layer waters of EMED showing larger salinification rates, this is not the case for the deep parts of the two sub-basins, where the salinification rate is relatively larger in the less salty waters of WMED than in the saltier EMED waters.

In addition, one may argue that the increased salinification of the basin may reduce stratification through the density increase, thus further enhancing diffusive fluxes. 

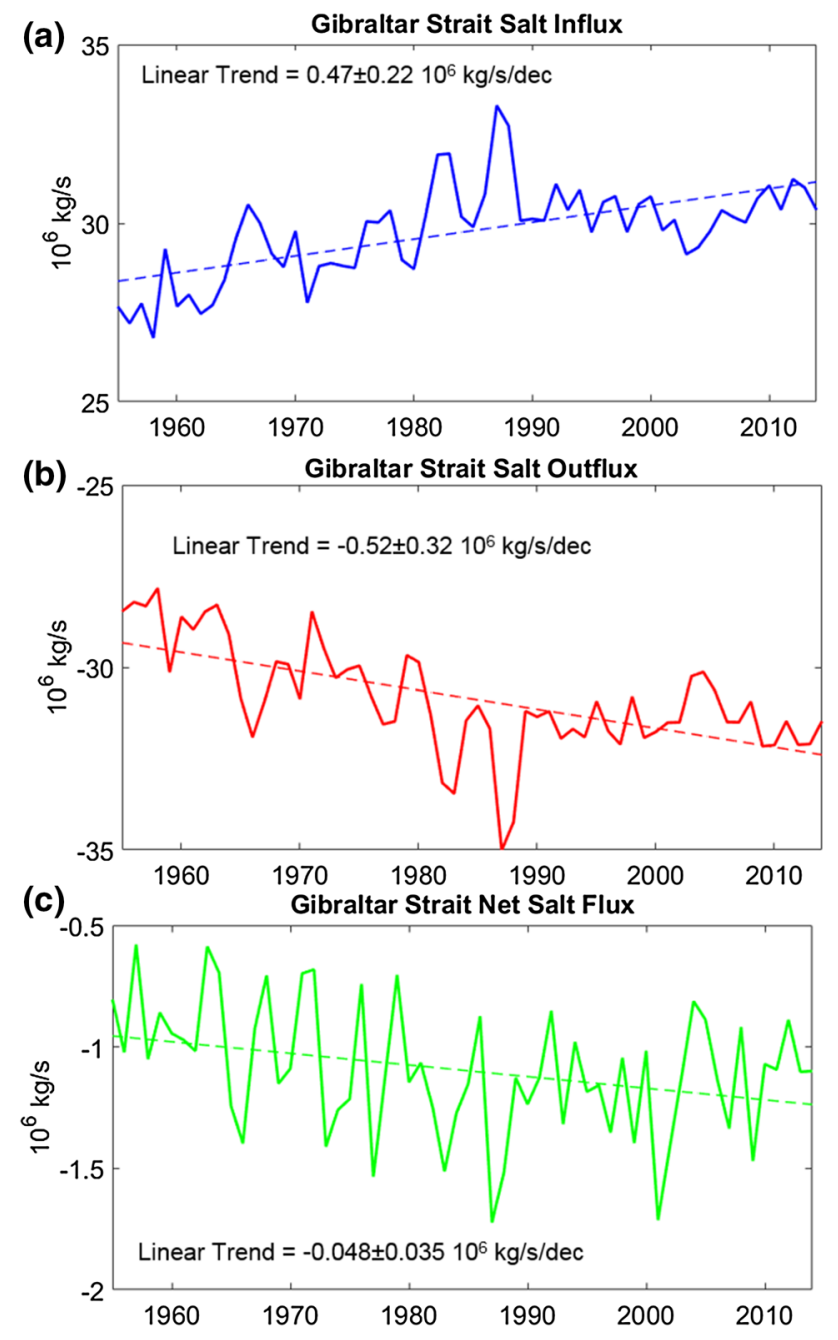

Fig. 7 Salt fluxes $(\mathrm{kg} / \mathrm{s})$ at the Gibraltar Strait derived from the Med Sea Physics Re-analysis for a upper layer inflow, b lower layer outflow and $\mathbf{c}$ Net water column salt flux. Yearly trends are also depicted

Salinification and warming trends over the second half of the twentieth century are shown to be almost density compensated in both the WMDW (Bethoux and Gentili 1999) and in the MOW within the Northeast Atlantic subtropical region (Potter and Lozier 2004), suggesting no significant long-term changes in Mediterranean Sea stratification before the 2000s. However large salinity-driven density increases are observed in the WMDW over the last 15 years mainly associated with the WMT (Schroeder et al. 2016; Somot et al. 2016; Houpert et al. 2016).

If there are indeed small changes in salt mixing the two methods considered here should infer comparable estimates of net evaporation increase. If we neglect changes in salt mixing (MIX $=0$ resulting in $\mathrm{WC}=\mathrm{FWT}$ from Eq. 5) the water mass transformation method infers a net evaporation increase of $0.00197 \pm 0.00083 \mathrm{~Sv}$ in Medatlas over $1950-2002$, that is $\sim 6 \%$ lower as compared with the net evaporation increase inferred from the approximate salt conservation equation $(\sim 0.00200 \pm 0.00098 \mathrm{~Sv})$. Similarly, for En4 over 1950-2015 net evaporation increase inferred by water mass transformation method $(\sim 0.00324 \pm 0.00120 \mathrm{~Sv})$ is $\sim 5 \%$ lower as compared with the net evaporation increase inferred from the approximate salt conservation equation $(\sim 0.00341 \pm 0.00109 \mathrm{~Sv})$. Slightly lower estimates inferred from the water mass transformation method for both datasets suggest a small increase in salt mixing over the considered period. However differences in estimates between the two methods are well within uncertainty estimates of the respective trends. This indicates a very small and not statistical significant contribution of salt mixing as compared to water cycle changes in producing the observed large changes in the Mediterranean volumetric distribution in salinity coordinates.

\section{Discussion}

Our estimate of net evaporation increase over 1950-2010 $(\sim 8 \%)$ derived by the Mediterranean total volume salt content increase in En4 and the net salt outflux from the ocean re-analysis is considerably lower (by a factor of $\sim 3$ to 4 ) as compared with our atmospheric reanalysis/river runoffbased estimate (20-30\%). We have much more confidence in our salinity-inferred estimate for a number of reasons. First, there is a much higher spatio-temporal coverage of salinity observations as compared to very sparse direct observations of surface freshwater fluxes. Second, there is much larger uncertainty in atmospheric reanalyses as compared to fully observationally-based salinity objective analyses. Uncertainty estimates obtained here for the long-term trends are much larger in reanalysis $E-P$ as compared to salt content timeseries (see Tables 2, 3). Moreover, in contrast with the two salinity datasets, large differences in the $E-P$ trend spatial patterns between the two reanalysis products considered here are evident in a number of regions, particularly in EMED. As mentioned before there are large uncertainties with atmospheric reanalyses arising from a variety of sources such as NWP model inconsistencies, discontinuity of timeseries of assimilated observations due to changes in the observing system (e.g. change or inclusion of new satellite sensors), or due to not explicitly taking into account every evolving forcing (e.g. GHG, aerosol, etc). Re-analyses are also often shown to be inconsistent with observations and to produce too-intense water cycling, overestimating both global $E$ and $P$ (e.g. Trenberth et al. 2007, 2011; Schanze et al. 2010; Skliris et al. 2014b).

However, as a caveat, we should still stress the limits to which objectively-analysed salinity fields can adequately represent long-term variability in some Mediterranean regions due to relatively poor sampling, in deep layers and 
(a)

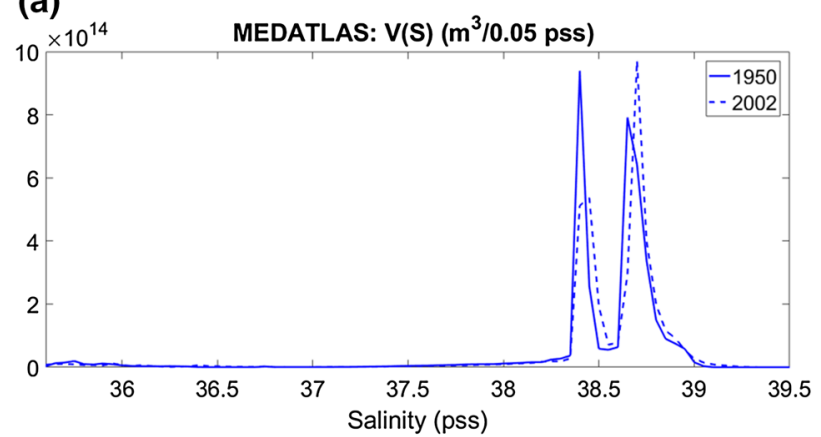

(b)

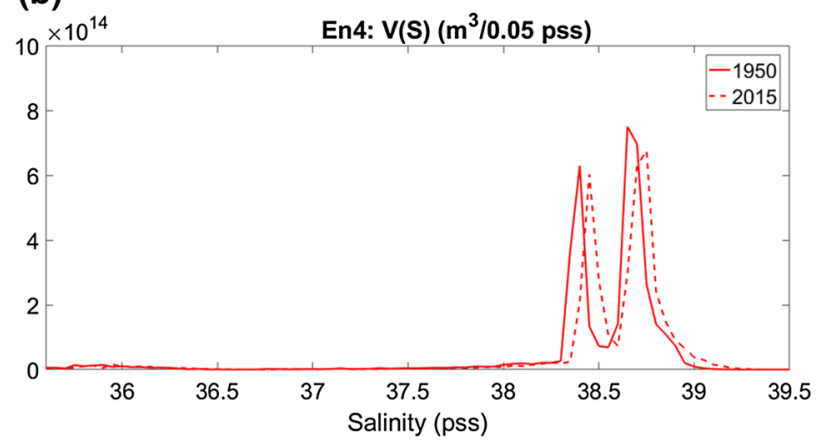

Fig. 8 Volumetric distribution in salinity space $V(S)$ in $\mathrm{m}^{3}$ per 0.05 pss salinity interval, for MEDATLAS for nominal years 1950 and 2002 (a) and for En4 for nominal years 1950 and 2015 (b). MTR rate $(d V(S) / d t)$ in Sv (c) and accumulated freshwater transport in salinity

over earlier decades in particular (Llasses et al. 2014). Also objective analysis/optimal interpolation techniques tend to underestimate long-term salinity anomalies, in areas of poor observational spatiotemporal coverage, in particular (e.g. Gille 2008). Comparison of trends derived from the two gridded MEDATLS/En4 datasets for specific regions/ layers and time periods against those estimated in other studies based on various observational networks indicated indeed an underestimation of salinity trends in most of cases ranging from $\sim 10$ to $50 \%$ (see Table 1). This suggests an underestimation of the basin total salt content increase and subsequently an underestimation of the net evaporation increase. Considering a maximum underestimation of $\sim 50 \%$ in volume averaged salinity trends, the inferred maximum net evaporation increase for En 4 is $\sim 12 \%$. This results in a net evaporation increase estimate ranging $8-12 \%$ over 1950-2010, which is still much lower as compared with that estimated from the two atmospheric reanalyses and the observed river runoff change (i.e. 20-30\%). Another source of uncertainty arises from the estimation of net salt flux change at the Gibraltar Strait from the ocean reanalysis which involves the combination of various uncertainties including those associated with the atmospheric forcing, data assimilation, and open boundary conditions. Ocean reanalysis outputs are strongly affected by the quality of (c)

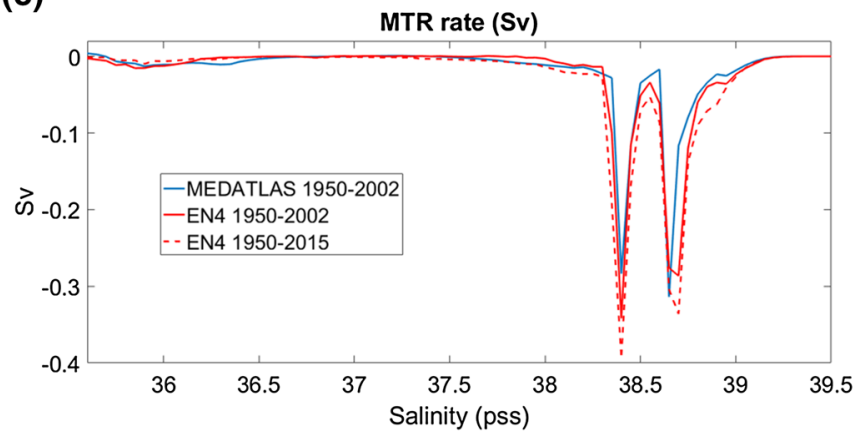

(d)

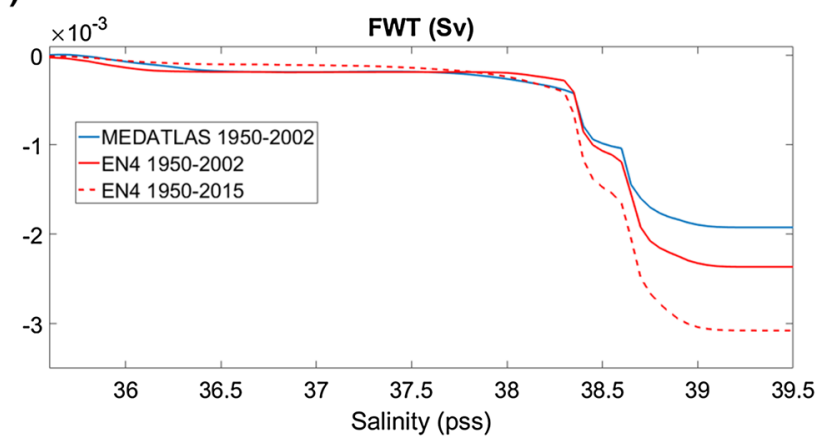

space $F W T(S)$ in Sv (d), derived from MEDATLAS (1950-2002) (blue lines), En4 over 1950-2002 (red lines), and En4 over 19502015 (red dashed lines)

atmospheric forcing. Large discrepancies have been found between the various atmospheric re-analysis/satellite derived datasets in producing long-term trends in surface water fluxes over the Atlantic ocean, even during the satellite-era when atmospheric models are well constrained by surface observations (Skliris et al. 2014b). In addition assimilation of salinity observations in the reanalysis model is not well constrained in some regions, in deep layers and in earlier decades of the record, in particular, due to relatively poor sampling. Basin salt content increase over 1955-2015 is more than two times larger in the ocean reanalysis as compared to that inferred from En4 over the same period (not shown). Moreover, although the ocean reanalysis model extends well into the Atlantic Ocean in order to better simulate exchanges at the Gibraltar Strait (Oddo et al. 2009), long-term changes are still strongly affected by lateral boundary conditions. The reanalysis model is one way nested at the Atlantic boundary to a low resolution global climatological model which controls salt inputs in the Mediterranean and may result in smoothing out long-term variability at the Gibraltar Strait.

The Gibraltar Strait exchange with volume transports of AW inflow and Mediterranean outflow of order $\sim 1 \mathrm{~Sv}$ (an order of magnitude larger with respect to the Dardanelles exchange flows) may significantly regulate basin salt content 


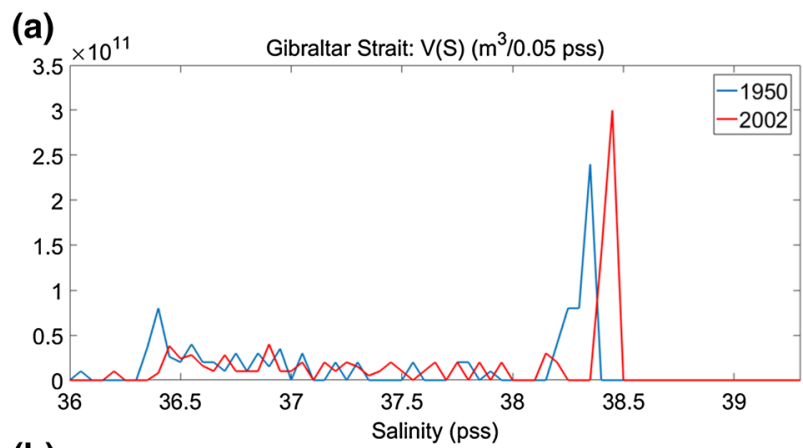

(b)

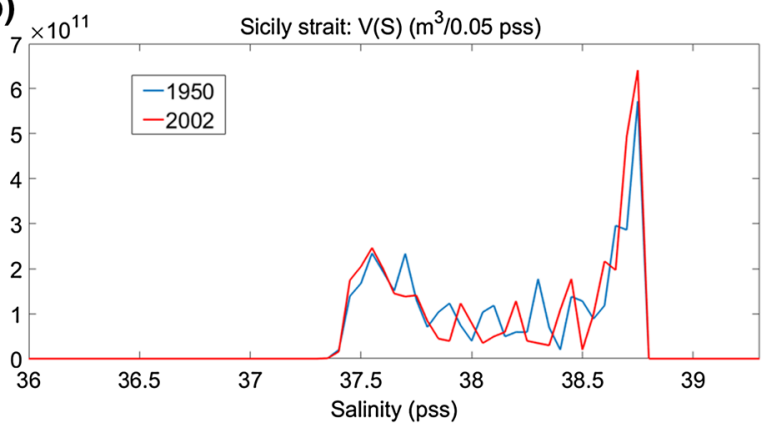

(c)

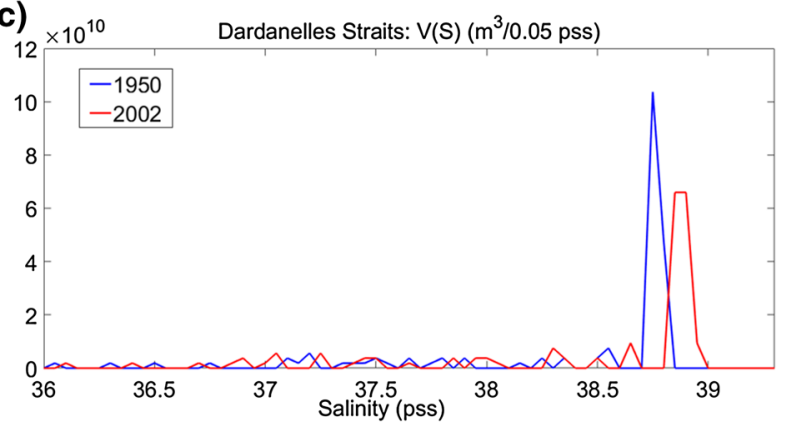

Fig. 9 Volumetric distribution in salinity space $V(S)\left(\mathrm{m}^{3} / 0.05 \mathrm{pss}\right)$ for nominal years 1950 (blue) and 2002 (red) (left panels) and MTR rate $(d V(S) / d t)$ in $\mathrm{Sv}$ (right panels) derived from MEDATLAS (1950-

variations. The ocean reanalysis used here showed increasing salt fluxes in both the upper (inflowing) and lower (outflowing) layers at the Gibraltar Strait. Increasing salt outflux to the Atlantic ocean is consistent with our water mass transformation analysis at the Strait showing large negative freshwater transformation in the lower layer suggesting a strong salinification of the Mediterranean outflow. This is also consistent with long-term salinity observations both near the Gibraltar exit (Millot et al. 2006) and along the MOW pathway in the Atlantic (Curry et al. 2003; Potter and Lozier 2004; Skliris et al. 2014b). A salt outflux increase at the straits is also expected when net evaporation increases over the Mediterranean surface. Long-term numerical experiments of the Mediterranean thermohaline circulation imposing an abrupt net evaporation increase show that the net salt outflow at the Gibraltar Strait gradually increases together with the basin-average salinity, partially compensating for (d)

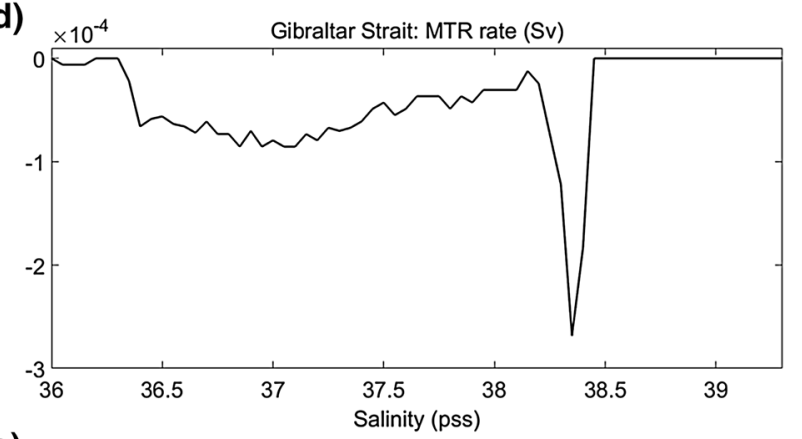

(e)

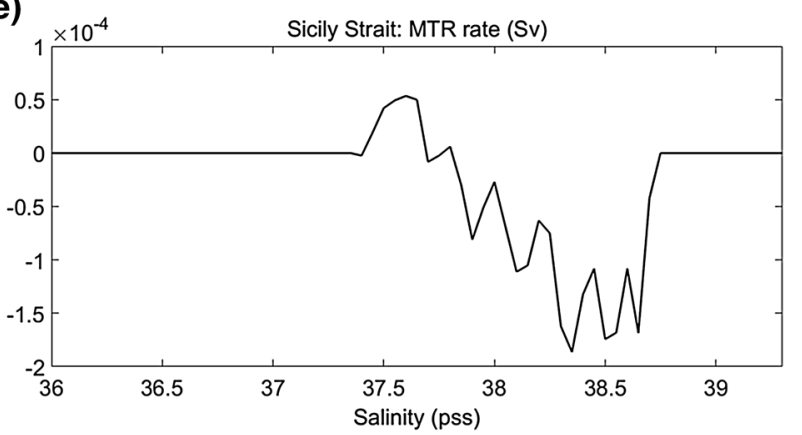

(f)

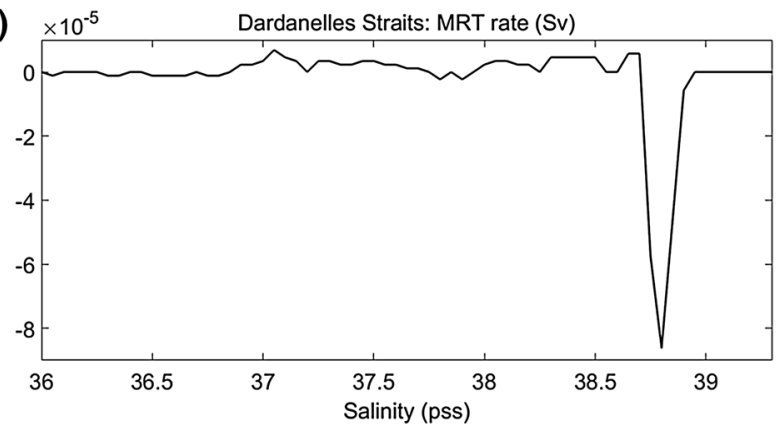

2002), for the Gibraltar Strait (a, d), Sicily Strait (b, e), and Dardanelles Strait $(\mathbf{c}, \mathbf{f})$, respectively

the basin salt content increase due to the freshwater loss through the surface (Myers and Haines 2002; Skliris and Lascaratos 2004; Skliris et al. 2007; Somot et al. 2006). However, this is a slow process as the characteristic time scale response of the Mediterranean Sea deep thermohaline circulation to an abrupt net evaporation increase of order $5-10 \%$ to reach a new freshwater balance is of the order of 70-100 years (Myers and Haines 2002; Skliris et al. 2007).

Increased salt influx by AW in the ocean reanalysis is also consistent with both our water mass transformation analysis and salinity observations around the Gibraltar strait. There is strong evidence of a long-term salinification of the upper layer of the eastern part of subtropical North Atlantic (Skliris et al. 2014b) which feeds the AW inflow in the Mediterranean Sea, whilst recent studies show a strong inter-annual salinification of the surface Atlantic waters adjacent to the Gibraltar Strait during the 2000s (Millot 2007; Soto-Navaro 
et al. 2012). Concerning the Dardanelles BSW inflow there even less observational evidence (as compared to Gibraltar Strait) to assess long-term changes. Stanev and Peneva (2002) investigating the long-term variations of Bosphorus transport showed an increasing trend over the second half of the twentieth century, indicating that the Aegean Sea was dominated by higher outflow from the Black Sea contributing to a long-term dilution of this regional basin. This is consistent with both the two salinity datasets used here showing a small but statistically significant freshening in the upper layer of the Northern Aegean Sea.

At multi-decadal scales, our results show very small water mass transformation rates at low salinities representative of inflowing AW and BSW (salinities $<36.5$ pss) as compared to transformation rates of typical Mediterranean water masses (salinities $>38.3$ pss) (see Fig. 8). Local volumetric distributions for the Gibraltar and Dardanelles Straits show that the range of salinity in the local water masses is far from the typical high salinities of intermediate/deep waters formed in both sub-basins (see Fig. 9). Local water mass transformation analysis in the straits also shows a very large negative freshwater transformation in the lower layer indicating the presence of much saltier outflowing waters of Mediterranean origin as compared with very small transformation rates (and even positive transformations of freshwater in the case of the Dardanelles straits indicating net freshening) in the upper layer inflowing waters from the adjacent basins (Fig. 9).

The ocean reanalysis applied here shows that the longterm salt outflux increase through the lower layer at the Gibraltar Strait is almost balanced by the salt influx increase in the upper layer resulting in a very small net salt outflux increase with the equivalent basin salt content increase being about only $5 \%$ of the actual basin salt content increase in En4. This indicates that net salt flux change at the Gibraltar Strait has a very small contribution in changing the Mediterranean salinity with respect to the local water cycle change.

\section{Conclusions}

Based on $E, P$ reanalysis and river runoff observational data we deduced a drastic increase in net evaporation of the Mediterranean Sea of 20-30\% over 1950-2010 attributed to changes in all three water cycle components. Based on the total salt content change (derived from En4 salinity) and increasing net salt transport from the Mediterranean to the Atlantic ocean (derived from the ocean reanalysis) we infer a net evaporation increase ranging $~ 8-12 \%$ over $1950-2010$. Water mass transformation analysis based on salinity observations shows that the net evaporation increase is by far the largest contributor in the salinification of the basin as compared to changes in the salt fluxes at the straits. The ocean re-analysis used here indicates that the salt outflux increase through the lower layer at the Gibraltar Strait due to deep/intermediate layer salinity increases in the basin is almost balanced by an AW salt influx increase in the upper layer. This finding is consistent with various studies showing strong salinification of waters feeding the AW inflow into the Mediterranean Sea. The equivalent salt content increase due to this net salt outflux in Med Sea reanalysis is only $\sim 5 \%$ of the observed basin salt content increase (En4) over 1950-2010. This is consistent with our findings from the application of water mass transformation method which clearly indicate that salt fluxes at the straits play a minor role in the strong salinification of the basin, which is largely driven by the local water cycle change.

The salinity-based estimate of net evaporation increase over the Mediterranean of $\sim 8-12 \%$ over $1950-2010$ is considerably larger than salinity-inferred estimates of global ocean water cycle amplification since the 1950 s (e.g. 4\% over 1950-2000, Durack et al. 2012; 2\% over 1950-2010; Skliris et al. 2014b, 2016). Coupled Model Intercomparison Project Phase 5 (CMIP5) historical simulations also show an increase in net evaporation of the Mediterranean Sea over the second half of the twentieth century which has already exceeded the range of internal variability (Mariotti et al. 2015). However CMIP5 historical simulations largely underestimate the amplitude of Mediterranean Sea $E-P$ anomalies as compared to observations/reanalyses (Mariotti et al. 2015). Coupled Atmosphere-Ocean Regional Climate Models also have difficulties to reproduce the observed evaporation and salinity trends in the Mediterranean Sea (Sevault et al. 2014; Ruti et al. 2016). Climate model projections show increasing rates of evaporation and salinification of the Mediterranean Sea over the twenty-first century under anthropogenic greenhouse gas emission scenarios (Giorgi and Lionello 2008; Somot et al. 2008; Mariotti et al. 2008, 2015; Adloff et al. 2015). Taking into account that our results indicate much stronger net evaporation increase than the coupled climate models over the historical period may suggest that future drying and salinification of the basin could be considerably larger than that projected by the current generation of coupled climate models. Excessive evaporation together with strong warming of the basin are expected to have far-reaching environmental and societal impacts in this region.

Acknowledgements This work is part of the UK Natural Environment Research Council funded project "CLimate scale analysis of Air and Water masses" (CLAW, Grant no.: NE/K012932/1).

Open Access This article is distributed under the terms of the Creative Commons Attribution 4.0 International License (http://creativecommons.org/licenses/by/4.0/), which permits unrestricted use, distribution, and reproduction in any medium, provided you give appropriate credit to the original author(s) and the source, provide a link to the Creative Commons license, and indicate if changes were made. 


\section{References}

Adani M, Dobricic S, Pinardi N (2011) Quality assessment of a 1985-2007 Mediterranean sea reanalysis. J Ocean Atmos Tech 28:569-589

Adloff F, Somot S, Sevault F et al (2015) Mediterranean Sea response to climate change in an ensemble of twenty first century scenarios. Clim Dyn 45:2775-2802. https://doi.org/10.1007/ s00382-015-2507-3

Bethoux JP, Gentili B (1999) Functionning of the Mediterranean Sea: past and present changes related to freshwater input and climate changes. J Mar Syst 20:33-47

Béthoux JP, Gentili B, Tailliez D (1998) Warming and freshwater budget change in the Mediterranean since the 1940s, their possible relation to the greenhouse effect. Geophys Res Lett 25(7):1023-1026

Borghini M, Bryden H, Schroeder K, Sparnocchia S, Vetrano A (2014) The Mediterranean is becoming saltier. Ocean Sci 10:693-700

Boyer TP, Levitus S, Antonov JI, Locarnini RA, Garcia HE (2005) Linear trends in salinity for the World Ocean, 1955-1998. Geophys Res Lett 32:L01604. https://doi.org/10.1029/2004GL021791

Bryden H, Schroeder K, Borghini M, Vetrano A, Sparnocchia S (2014) Mixing in the deep waters of the western Mediterranean. In: Borzelli GLE (eds) The Mediterranean Sea: temporal variability and spatial patterns. American Geophysical Union Monograph Series 105

Cherchi A, Navarra A (2007) Sensitivity of the Asian summer monsoon to the horizontal resolution: differences between AMIP-type and coupled model experiment. Clim Dyn 28(2):273-290. https://doi. org/10.1007/s00382-006-0183-Z

Compo GP, Whitaker JS, Sardeshmukh PD et al (2011) The twentieth century reanalysis project. Q J R Meteorol Soc 137:1-28

Cook BI, Anchukaitis KJ, Touchan R, Meko DM, Cook ER (2016) Spatiotemporal drought variability in the Mediterranean over the last 900 years. J Geophys Res Atmos 121:2060-2074. https://doi. org/10.1002/2015JD023929

Curry R, Dickson B, Yashayaev I (2003) A change in the freshwater balance of the Atlantic Ocean over the past four decades. Nature 426(6968):826-828

Dai A, Qian T, Trenberth KE, Milliman JD (2009) Changes in continental freshwater discharge from 1948 to 2004. J Climate 22:2773-2792. https://doi.org/10.1175/2008JCLI2592.1

Dobricic S, Pinardi N (2008) An oceanographic three-dimensional variational data assimilation scheme. Ocean Model 22:89-105

Durack PJ, Wijffels SE, Matear RJ (2012) Ocean salinities reveal strong global water cycle intensification during 1950 to 2000 . Science 336:455-458

Fekete BM, Vorosmarty CJ, Grabs W (1999) Global, composite runoff fields based on observed river discharge and simulated water balances, Tech. Rep. 22, Global Runoff Data Cent., Koblenz

Fratianni C, Simoncelli S, Pinardi N, Cherchi A, Grandi A, Dobricic S (2015) Mediterranean RR 1955-2015 (Version 1). [Data set]. Copernicus Monitoring Environment Marine Service (CMEMS). https://doi.org/10.25423/ MEDSEA_REANALYSIS_PHY_006_009

Gille ST (2008) Decadal-scale temperature trends in the southern hemisphere ocean. J Clim 21(18):4749-4765. https://doi.org/10.1175 /2008JCLI2131.1

Giorgi F (2006) Climate change hot-spots. Geophys Res Lett 33:L08707

Giorgi F, Lionello P (2008) Climate change projections for the Mediterranean region. Glob Planet Change 63(2-3):90-104. https:// doi.org/10.1016/j.gloplacha.2007.09.005

Good SA, Martin MJ, Rayner NA (2013) Quality controlled ocean temperature and salinity profiles and monthly objective analyses with uncertainty estimates. J Geophys Res Oceans 118:6704-6716
Hamon M, Beuvier J, Somot S, Lellouche J-M, Greiner E 3, Jordà G, Bouin G, Arsouze M-N, Béranger T, Sevault K, Dubois F, Drevillon C, Drillet M (2016) Design and validation of MEDRYS, a Mediterranean Sea reanalysis over the period 1992-2013. Ocean Sci 12:577-599. https://doi.org/10.5194/ os-12-577-2016

Hatzianastasiou N, Papadimas C, Lolis C, Bartzokas A, Levizzani V, Pnevmatikos J, Basil D, Katsoulis B (2016) Spatial and temporal variability of precipitation over the Mediterranean Basin based on 32-year satellite Global Precipitation Climatology Project data, part I: evaluation and climatological patterns. Int J Climatol 36:4741-4754

Hegerl G et al (2015) Challenges in quantifying changes in the global water cycle. Bull Am Meteorol Soc 96:1097-1115. https://doi. org/10.1175/BAMS-D-13-00212.1

Held IM, Soden BJ (2006) Robust responses of the hydrological cycle to global warming. J Clim 19:5686-5699

Helm KP, Bindoff NL, Church JA (2010) Changes in the global hydrological-cycle inferred from ocean salinity. Geophys Res Lett 37:L18701. https://doi.org/10.1029/2010GL044222

Hosoda S, Suga T, Shikama N, Mizuno K (2009) Global surface layer salinity change detected by Argo and its implication for hydrological cycle intensification. J Oceanogr 65:579-586. https://doi.org/10.1007/s10872-009-0049-1

Houpert L, Durrieu de Madron X, Testor P, Bosse A, D'Ortenzio F, Bouin MN, Coppola L (2016) Observations of open-ocean deep convection in the northwestern Mediterranean Sea: Seasonal and interannual variability of mixing and deep water masses for the 2007-2013 Period. J Geophys Res Oceans 121(11):8139-8171

Jordá G, Von Schuckmann K, Josey SA, Caniaux G, García-Lafuente J, Sammartino S, Adloff F (2017) The Mediterranean Sea heat and mass budgets: estimates, uncertainties and perspectives. Progr Oceanogr 156:174-208

Kelley C, Ting M, Seager R, Kushnir Y (2012) The relative contributions of radiative forcing and internal climate variability to the late 20th Century winter drying of the Mediterranean region. Clim Dyn 38(9-10):2001-2015. https://doi.org/10.1007/ s00382-011-1221-z

Kistler R, Collins W, Saha S et al (2001) The NCEP-NCAR 50-year reanalysis: monthly means CD-ROM and documentation. Bull Am Meteorol Soc 82:247-267

Klein B, Roether W, Manca BB, Bregant D, Beitzel V, Kovacevic V, Luchetta A (1999) The large deep water transient in the Eastern Mediterranean. Deep Sea Res I 46:371-414

Krahmann G, Schott F (1998) Long-term increases in Western Mediterranean salinities and temperatures: anthropogenic and climatic sources. Geophys Res Lett 25(22):4209-4212

Llasses J, Jordà G, Gomis D (2014) Skills of different hydrographic networks to capture changes in the Mediterranean Sea at climate scales. Clim Res 63:1-18. https://doi.org/10.3354/cr01270

Ludwig L, Dumont E, Meybeck M, Heussner S (2009) River discharges of water and nutrients to the Mediterranean and Black Sea: major drivers for ecosystem changes during past and future decades? Prog Oceanogr 80:199-217

Manca B, Burca M, Giorgetti A, Coatanoan C, Garcia M-J, Iona A (2004) Physical and biochemical averaged vertical profiles in the Mediterranean regions: an important tool to trace the climatology of water masses and to validate incoming data from operational oceanography. J Mar Syst 48:83-116. https://doi. org/10.1016/j.marsys.2003.11.025

Mariotti A (2010) Recent changes in the Mediterranean water cycle: a pathway toward long-term regional hydroclimatic change? J Clim 23:1513-1525

Mariotti A, Strugglia MV, Zeng L, Lau KM (2002) The hydrological cycle in the Mediterranean region and implications for the water budget of the Mediterranean sea. J Clim 15:1674-1690 
Mariotti A, Zeng N, Yoon J, Artale V, Navarra A, Alpert P, Li L (2008) Mediterranean water cycle changes: transition to drier 21st century conditions in observations and CMIP3 simulations. Environ Res Lett 3:044001. https://doi.org/10.1088/1748-9326/3/04400

Mariotti A, Pan Y, Zeng N, Alessandri A (2015) Long-term climate change in the Mediterranean region in the midst of decadal variability. Clim Dyn 44:1437-1456

MEDAR Group (2002) Mediterranean and Black Sea database of temperature, salinity and biogeochemical parameters climatological atlas. IFREMER, Brest, 4 CDROM

Millot C (2007) Interannual salinification of the Mediterranean inflow. Geophys Res Lett 34:L21609. https://doi. org/10.1029/2007GL031179

Millot C, Candela J, Fuda JL, Tber Y (2006) Large warming and salinification of the Mediterranean outflow due to changes in its composition. Deep Sea Res 53:656-666

Myers PG, Haines K (2002) Stability of the Mediterranean's thermohaline circulation under modified surface evaporative fluxes. J Geophys Res 107(C3):3021. https://doi.org/10.1029/2000JC000550

Nastos PT (2011) Trends and variability of precipitation within the Mediterranean region, based on Global Precipitation Climatology Project (GPCP) and ground based datasets. Adv Res Aquat Environ 1:67-74. https://doi.org/10.1007/978-3-642-19902-8_7

Oddo P, Adani M, Pinardi N, Fratianni C, Tonani M, Pettenuzzo D (2009) A nested Atlantic-Mediterranean Sea general circulation model for operational forecasting. Ocean Sci 5:461-473

Ozer T, Gertman I, Kress N, Silverman J, Herut B (2016) Interannual thermohaline (1979-2014) and nutrient (2002-2014) dynamics in the Levantine surface and intermediate water masses, SE Mediterranean Sea. Glob Planet Change. https://doi.org/10.1016/j. gloplacha.2016.04.001

Potter R, Lozier S (2004) On the warming and salinification of the Mediterranean outflow waters in the North Atlantic. Geophys Res Lett 31:L01202. https://doi.org/10.1029/2003GL018161

Rayner NA, Parker DE, Horton EB, Folland CK, Alexander LV, Rowell DP, Kent EC, Kaplan A (2003) Global analyses of sea surface temperature, sea ice, and night marine air temperature since the late nineteenth century. J Geophys Res 108:4407. https://doi. org/10.1029/2002JD002670

Rixen M, Beckers J-M, Levitus S et al (2005) The Western Mediterranean deep water: a proxy for climate change. Geophys Res Lett 32:L12608. https://doi.org/10.1029/2005GL022702

Rohling EJ, Bryden HL (1992) Man-induced salinity and temperature increases in western Mediterranean water. J Geophys Res 97:11191-11198

Romanou A, Tselioudis G, Zerefos CS, Clayson C, Curry JA, Andersson A (2010) Evaporation-precipitation variability over the Mediterranean and the Black Seas from satellite and reanalysis estimates. J Clim 23:5268-5287

Ruti PM, Somot S, Giorgi F, Dubois C, Flaounas E, Obermann A, Dell'Aquila A, Pisacane G, Harzallah A, Lombardi E, Ahrens B, Akhtar N, Alias A, Arsouze T, Aznar R, Bastin S, Bartholy J, Béranger K, Beuvier J, Bouffies-Cloché S, Brauch J, Cabos W, Calmanti S, Calvet J-C, Carillo A, Conte D, Coppola E, Djurdjevic V, Drobinski P, Elizalde-Arellano A, Gaertner M, Galàn P, Gallardo C, Gualdi S, Goncalves M, Jorba O, Jordà G, L'Heveder $\mathrm{B}$, Lebeaupin-Brossier C, Li L, Liguori G, Lionello P, Maciàs D, Nabat P, Onol B, Raikovic B, Ramage K, Sevault F, Sannino G, Struglia MV, Sanna A, Torma C, Vervatis V (2016) MEDCORDEX initiative for Mediterranean Climate studies. Bull Am Meteorol Soc 97(7):1187-1208. https://doi.org/10.1175/ BAMS-D-14-00176.1

Sanchez-Gomez E, Somot S, Josey SA, Dubois C, Elguindi N, Déqué M (2011) Evaluation of Mediterranean Sea water and heat budgets simulated by an ensemble of high resolution regional climate models. Clim Dyn 37:2067-2086
Schanze JJ, Schmitt RW, Yu LL (2010) The global oceanic freshwater cycle: a state-of-the-art quantification. J Mar Res 68:569-595

Schroeder K, Garcìa-Lafuente J, Josey SA, Artale V, BuongiornoNardelli B, Gacic M, Gasparini GP, Herrmann M, Lionello P, Ludwig W, Millot C, Ozsoy E, Pisacane G, Sanchez-Garrido JC, Sannino G, Santoleri R, Somot S, Struglia M, Stanev E, TaupierLetage I, Tsimplis M, Vargas-Yanez M, Zervakis V, Zodiatis G (2012) Circulation of the Mediterranean Sea and its variability (Chap. 4). In Lionello P (ed), Mediterranean climate variability. Elsevier, Amsterdam, pp 187-256

Schroeder K, Chiggiato J, Bryden HL, Ismail SB (2016) Abrupt climate shift in the Western Mediterranean Sea. Sci Rep 6:23009. https://doi.org/10.1038/srep23009

Schroeder C, Chiggiato J, Josey S, Borghini M, Aracri S, Sparnoccia S (2017) Rapid response to climate change in a marginal sea. Sci Rep 7:4065

Sevault F, Somot S, Alias A, Dubois C, Lebeaupin-Brossier C, Nabat P, Decharme B (2014) A fully coupled Mediterranean regional climate system model: design and evaluation of the ocean component for the 1980-2012 period. Tellus A 66:23967

Skliris N (2014a) Past, present, and future patterns of the thermohaline circulation and characteristic water masses of the Mediterranean Sea. In: Goffredo S, Dubinsky Z (eds) The Mediterranean Sea: its history and present challenges. Springer, Berlin, pp 29-48. https:// doi.org/10.1007/978-94-007-6704-1_3

Skliris N, Lascaratos A (2004) Impacts of the Nile River damming on the thermohaline circulation and water mass characteristics of the Mediterranean Sea. J Mar Syst 52:121-143

Skliris N, Sofianos S, Lascaratos A (2007) Hydrological changes in the Mediterranean Sea in relation to changes in the freshwater budget: a numerical modelling study. J Mar Syst 65:400-416

Skliris N, Sofianos S, Gkanasos A, Mantziafou A, Vervatis V, Axaopoulos P, Lascaratos A (2012) Decadal scale variability of sea surface temperature in the Mediterranean Sea in relation to atmospheric variability. Ocean Dyn 62:13-30

Skliris N, Marsh R, Josey SA et al (2014b) Salinity changes in the World Ocean since 1950 in relation to changing surface freshwater fluxes. Clim Dyn 43:709-736

Skliris N, Zika JD, Nurser G, Josey SA, Marsh R (2016) Global water cycle amplifying at less than the Clausius-Clapeyron rate. Sci Rep 6:38752. https://doi.org/10.1038/srep38752

Somot S, Sevault F, Déqué M (2006) Transient climate change scenario simulation of the Mediterranean Sea for the twenty-first century using a high-resolution ocean circulation model. Clim Dyn 27:851-879

Somot S, Sevault F, Déqué M, Crépon M (2008) 21st century climate change scenario for the Mediterranean using a coupled atmosphere-ocean regional climate model. Glob Planet Change 63:112-126

Somot S, Houpert L, Sevault F, Testor P, Bosse A, Taupier-Letage I, de Madron XD (2016). Characterizing, modelling and understanding the climate variability of the deep water formation in the NorthWestern Mediterranean Sea. Clim Dyn. https://doi.org/10.1007/ s00382-016-3295-0

Soto-Navarro J, Criado-Aldeanueva J, Sánchez-Garrido F, GarcíaLafuente JC (2012) Recent thermohaline trends of the Atlantic waters inflowing to the Mediterranean Sea. Geophys Res Lett 39:L01604. https://doi.org/10.1029/2011GL049907

Stanev E, Peneva E (2002) Regional sea level response to global climate change: Black Sea exmples. Glob Planet Change 32:33-47

Terray L, Corre L, Cravatte S, Delcroix T, Reverdin G, Ribes A (2012) Near-surface salinity as nature's rain gauge to detect human influence on the tropical water cycle. J Clim 25:958-977

Theocharis A, Nittis K, Kontoyiannis H, Papageorgiou E, Balopoulos E (1999) Climatic changes in the Aegean Sea influence the Eastern 
Mediterranean thermohaline circulation (1986-1997). Geophys Res Lett 26(11):1617-1620

Trenberth KE, Smith L, Qian T, Dai A, Fasullo J (2007) Estimates of the global water budget and its annual cycle using observational and model data. J Hydrometeorol 8:758-769

Trenberth KE, Fasullo J, Mackaro J (2011) Atmospheric moisture transports from ocean to land and global energy flows in reanalyses. J Clim 24(18):4907-4924. https://doi.org/10.1175/201 1JCLI4171.1

Tsimplis MN, Josey SA (2001) Forcing of the Mediterranean Sea by atmospheric oscillations over the North Atlantic. Geophys Res Lett 28:803-806. https://doi.org/10.1029/2000GL012098

Vargas-Yanez M, Zunino P, Benali A, Delpy M, Pastre F, Moya F, Garcia-Martinez MC, Tel E (2010) How much is the western Mediterranean really warming and salting? J Geophys Res 115:C04001. https://doi.org/10.1029/2009JC005816

Walin G (1977) A theoretical framework for the description of estuaries. Tellus 29(2):128-136

Walin G (1982) On the relation between sea-surface heat flow and thermal circulation in the ocean. Tellus 34:187-195

Xie P, Arkin PA (1997) Global precipitation: a 17-year monthly analysis based on gauge observations, satellite estimates, and numerical model outputs. Bull Amer Meteor Soc 78:2539-2558. https://doi. org/10.1175/1520-0477

Zika JD, Skliris N, Nurser G, Josey SA, Mudryk L, Laliberte F, Marsh R (2015) Maintenance and broadening of the ocean's salinity distribution by the water cycle. J Clim 28(24):9550-9560. https:// doi.org/10.1175/JCLI-D-15-0273.1 